\title{
Nanomedicine
}

\section{AN OVERVIEW OF NANOMEDICINES FOR NEURON \\ TARGETING}

\begin{tabular}{|r|l|}
\hline Journal: & Nanomedicine \\
\hline Manuscript ID & NNM-2020-0088.R2 \\
\hline Manuscript Type: & Review \\
\hline Keywords: & $\begin{array}{l}\text { Nanoparticles, neurons, targeted drug delivery, neuron-related diseases, } \\
\text { brain and neuron targeting }\end{array}$ \\
\hline
\end{tabular}

\section{SCHOLARONE \\ Manuscripts}




\title{
AN OVERVIEW OF NANOMEDICINES FOR NEURON TARGETING
}

\author{
Jesus Garcia-Chica ${ }^{1,4,6, \#}$, West Kristian D. Paraiso ${ }^{2, \#}$, Shihori Tanabe ${ }^{3}$, Dolors Serra ${ }^{4,5}$, Laura \\ Herrero $^{4,5}$, Núria Casals ${ }^{1,5}$, Jordi Garcia ${ }^{5,6}$, Xavier Ariza ${ }^{5,6}$, Sabina Quader $^{2, *}$, Rosalia \\ Rodriguez-Rodriguez ${ }^{1, *}$
}

${ }^{1}$ Basic Sciences Department, Faculty of Medicine and Health Sciences, Universitat Internacional de Catalunya, 08195 Sant Cugat del Vallès, Spain.

${ }^{2}$ Innovation Center of Nanomedicine, Kawasaki Institute of Industrial Promotion, Kawasaki, Kanagawa 210-0821 Japan

${ }^{3}$ Division of Risk Assessment, Center for Biological Safety and Research, National Institute of Health Sciences, Kawasaki, Kanagawa 210-9501 Japan

${ }^{4}$ Department of Biochemistry and Physiology, School of Pharmacy and Food Sciences, Institut de Biomedicina de la Universitat de Barcelona (IBUB), Universitat de Barcelona, E-08028 Barcelona, Spain.

${ }^{5}$ Centro de Investigación Biomédica en Red de Fisiopatología de la Obesidad y la Nutrición (CIBEROBN), Instituto de Salud Carlos III, E-28029 Madrid, Spain.

${ }^{6}$ Department of Inorganic and Organic Chemistry, Faculty of Chemistry, Institut de Biomedicina de la Universitat de Barcelona (IBUB), Universitat de Barcelona, E-08028 Barcelona, Spain.

\footnotetext{
\# These authors equally contributed to this work

*Corresponding authors: Sabina Quader (sabina-q@kawasaki-net.ne.jp) (Tel. +81-44-5895920 ) and Rosalía Rodríguez-Rodríguez (rrodriguez@uic.es) (Tel. +34-935-042-002)
}

\section{Financial \& competing interests disclosure}

This review was financially supported by the Joint Bilateral Project Japan-Spain (PCI2018092997/AEI Agencia Estatal de Investigación to R.R.-R and 19jm0210059h0002/AMED to S.Q.), by the Spanish Ministerio de Economía, Industria y Competitividad (MINECO) (SAF201782813-C3-3R to NC and RR-R, and SAF2017-83813-C3-1-R to DS and LH, cofounded by the European Regional Development Fund [ERDF]), the Centro de Investigación Biomédica en Red de Fisiopatología de la Obesidad y la Nutrición (CIBEROBN) (Grant CB06/03/0001 to DS), the Government of Catalonia (2017SGR278 to DS), and the Fundació La Marató de TV3 (20162731 to NC and 201627-30 to DS). The authors have no other relevant affiliations or financial involvement with any organization or entity with a financial interest in or financial conflict with the subject matter or materials discussed in the manuscript apart from those disclosed. 


\section{AN OVERVIEW OF NANOMEDICINES FOR NEURON TARGETING}

4 5

\section{Abstract}

7 Medical treatments of neuron-related disorders are limited due to the difficulty of targeting 8 brain cells. Major drawbacks are the presence of the blood-brain barrier and the lack of 9 specificity of the drugs for the diseased cells. Nanomedicine-based approaches provide 10 promising opportunities for overcoming these limitations. Although many previous reviews are 11 focused on brain targeting with nanomedicines in general, none of those are concerned 12 explicitly on the neurons, while, targeting neuronal cells in central nervous diseases is now one 13 of the biggest challenges in nanomedicine and neuroscience. We review the most relevant 14 advances in nanomedicine design and strategies for neuronal drug delivery that might 15 successfully bridge the gap between laboratory and bedside treatment in neurology.

17 Keywords: nanoparticles; targeted drug delivery; brain and neuron targeting; neuron-related 18 diseases 


\section{Introduction}

At this moment, many neuron-related diseases (e.g., neurodegenerative diseases, neuroendocrine disorders) are not adequately treated due to the lack of approaches to effectively reach the targets on specific neuronal populations. These central nervous system (CNS) pathologies have led to devastating implications on the human public health, since low availability or side effects of the drugs (e.g., due to unspecific delivery in other cells or tissues) limit the clinical effectiveness against the neuron-related disease. The difficulty in achieving improved clinical outcomes for CNS disorders relies on the inability to deliver therapeutically relevant doses of the therapeutic to diseased cells or regions [1-3]. One of the main obstacles for the delivery of systemically administered therapies into the brain is the Blood-Brain Barrier (BBB). Besides this barrier, exposure of the drug to cells or tissues out of the target cell implies side effects, toxicity, and loss of effectiveness of the therapy. Finally, chemical instability of potential drugs against neuronal diseases limits their use and claims the use of carriers protecting the drug until the delivery in the brain cells.

Nanomedicine-based approaches provide promising opportunities for overcoming these limitations and therefore improve the therapeutic efficacy of neuron-related diseases. The use of nanoparticles (NPs) as drug delivery carriers has been widely investigated in pre-clinical investigations and is now being applied in the clinical settings for selected CNS diseases [1,4-7] (Table1). These studies demonstrate that the use of different types of nanoformulations significantly overcomes the BBB crossing and improves CNS pharmacokinetic and distribution in brain areas in comparison to free drug [8,9]. In addition to overcoming BBB, surface decoration with specific ligands would allow "active targeting" to a brain cell type [10]. At this time, targeting neuronal cells in CNS pathologies remains one of the biggest challenges in nanomedicine and neuroscience.

Concerning the clinical application of nanoformulations targeting neuronal diseases, there is a clear gap between laboratory and bedside treatment. Currently, there are only a few nanomedicines already in clinical use and in the clinical pipeline to treat neurodegenerative disorders (Table 1). These nanomedicines are mainly based on the use of polymeric-based therapeutics, gold nanocrystals, and curcumin encapsulated in nano-micelles and nanoparticles of an inhibitor of alpha-secretase in Alzheimer's disease (AD) (APH-1105). However, these nanoformulations were not specifically designed to target neurons, and the mechanistic aspects and the plausible modifications to improve their clinical outcome are still poorly known. A major factor for the low number of nanomedicines to target neuronal diseases in clinical trials is the complexity of the design and development of these approaches, and thereby an exhaustive preclinical validation is required. Therefore, in the last years many efforts have been focused on the development and testing of neuronal-targeting nanomedicines in models of CNS disorders (particularly rodents) that could improve the clinical application of these nanoparticles into neurology.

In this review, we will describe the main nanomedicine-based approaches implemented to reach neurons and thereby treat CNS disorders. We will discuss the most recent advances on nanomedicine design, type of nanocarriers, therapeutic cargos, as well as strategies to target neurons in the treatment of neuronal diseases in vivo. A brief description on the hurdles in brain delivery is also included. Although previous reviews are focused on brain targeting with nanomedicines in general, none of them are concerned explicitly on the neurons. This review highlights some interesting evidence that might successfully bridge the gap between laboratory and bedside treatments. 


\section{The hurdles in brain delivery strategies}

The brain vasculature plays a crucial role as a barrier, transport, and distribution of micronutrients, macronutrients and oxygen to the CNS and CNS homeostasis. BBB is composed of specialized endothelial cells with specific properties that restrict the free movement of molecules, ions, and cells from blood to CNS. Besides, these endothelial cells facilitate the transport of toxic products from CNS to the blood. Both processes are critical for proper neuronal function and the protection of CNS from pathogens, toxins, inflammation, and diseases. Additional cells, such as neuroglial cells (astrocytes), pericytes, and neurons, and a discontinuous basal membrane, play a key role in the function and the maintenance of the BBB properties (Fig. 1). The low permeability of the BBB is the major hurdle for drug delivery to brain cells.

\subsection{Blood-Brain Barrier}

Some structural features make the BBB selectively permeable. The endothelial cells of the cerebral microvessels are sealed together by tight junctions that limit the free diffusion of molecules, and ions across the BBB [11] (Fig. 1). Tight junctions are constituted by the trans membrane and cytoplasmic proteins that include claudin, occludin, junction adhesion molecules and accessory proteins involved in the formation of more adherent junctions [10]. This strong, cohesive system maintains endothelial cells tightly connected. It limits the paracellular transport (passage between endothelial cells) and also renders polarization of these endothelial cells where the luminal plasma membrane is directed towards blood. The movement between the blood and the brain is controlled through tightly regulated cellular transport (termed transcellular transport). The transcellular transport involves the passive diffusion of lipophilic molecules and transporters. There are two types of transporters: i) carrier-mediated transporters of endogenous molecules and ii) the efflux transporters. Most of the carrier-related transporters are related to the transport of nutrients, peptides, and proteins. The CNS endothelial cells express a wide variety of these nutrient transporters, such as glucose transporter-1 (GLUT-1), which is responsible for the glucose uptake and SLC16a1 for lactate and pyruvate transport. In addition, the CNS endothelial cells express several receptor-mediated transport systems, including low-density receptor-related lipoprotein (LPR)1/LPR8, transferrin receptor, and insulin receptor (extensively reviewed in $[12,13]$ ). Many of these transport systems have been explored as a possible gate for brain-directed drug delivery $[14,15]$. Efflux transporters are located in the luminal compartment, and they transport a wide array of molecules from CNS into the blood. They are involved in the transport of neurotoxic lipid-soluble molecules or drugs out to the brain. Inhibition of these efflux pumps have been explored as new strategies for brain targeting [16,17].

\subsection{Astrocytes and pericytes}

Astrocytes are the most abundant glial cell type in the CNS and support neuron function by regulating neurotransmitters and electrolyte balance. Astrocytes envelop the BBB endothelium, and they have cellular protrusions that cover the blood vessels and neuronal synapses, promoting a direct link between vasculature and neuronal circuits [18]. It has been described as a direct contact between the end-feet of astrocytes and the abluminal part of the CNS microvessels that greatly enhance endothelial cell tight junctions contributing to an increase in barrier integrity [19]. Besides, astrocytes express a range of proteins that control water homeostasis in the CNS and secrete factors (e.g., angiotensin-1) that play a role in the barrier properties of CNS endothelial cells [20]. 
Pericytes surround the CNS endothelial cells on the abluminal side and they can act as macrophages regulating proliferation, migration, differentiation, vascular branching, and survival of endothelial cells and can regulate blood-flow of capillaries [21]. Pericytes have a close physical association with CNS endothelium and are involved in the formation of gap junctions, peg-and-socket junctions [22], which makes pericytes the key cells for the BBB maintenance and stabilization and tight junctions development.

Altogether, astrocytes and pericytes may play an important role in the maintenance of the BBB structure and function and BBB permeability, respectively, and therefore might be taken into consideration for effective drug delivery.

\subsection{Neurons}

Neurons are major electrically excitable cells in the brain that process and transmit information to other cells through synapses. They are important therapeutic targets as they are usually impaired in most brain pathologies: stroke or traumatic brain injury, neurodegenerative diseases, psychiatric disorders and epilepsy, among others.

Drug delivery specifically to neurons is challenging because i) neurons are only around $10 \%$ of all brain cells, ii) they are non-phagocytic compared to glial cells, and iii) there are different kinds of neurons with completely different functions. Since the final aim is targeting one specific group of disease-related neurons in the brain, it is of high importance to develop drug delivery strategies for targeting specifically impaired neurons to minimize drug side-effects and improve therapeutic efficiency [1].

Specific characteristics of neurons and of the NP itself can help in the design of delivery systems, particularly nanoplatforms, for targeting neurons over non-neuronal cells:

i. Neuronal uptake of lipid nanoparticles (LNP) is facilitated by adsorption of ApoE secreted by astrocytes, to the NPs, which can be recognized by LDL receptors and subsequent endocytosis into neurons in vivo [23].

ii. Neurons show a high abundance of GT1b gangliosides and sphingophospholipids in their plasma membrane. Tet1 is a 12-amino acid peptide that exhibits high affinity for those molecules and has been demonstrated to bind mainly to neural progenitor cells in vivo [24].

iii. The nicotinic acetylcholine receptor ( $\mathrm{AAChR})$ and the neuronal cell adhesion molecule (NCAM) present in the plasma membrane of neurons facilitate the entry of rabies virus through the binding of a viral glycoprotein, which is responsible for the neurotrophic nature of the infection. Drug delivery systems using this glycoprotein can offer a nontoxic and non-invasive approach for the targeting of neurons [25,26].

iv. Neurons are highly receptive to exosomes. Exosomes are extracellular vesicles involved in transmitting reciprocal signals between cells, can cross the BBB, and can be loaded with a wide range of cargos (e.g., drugs, nucleic acids, and proteins). Therefore, they are a promising tool for therapeutic delivery strategies. It has recently been shown that exosomes released by activated glutamatergic neurons bind selectively to other neurons instead of being internalized by glial cells $[27,28]$. The comprehension of the exosome mechanisms that drive neuron selectivity will provide new tools for specific targeting to neurons.

Since these characteristics are shared by most of the neurons, neuron subtype-delivery systems must be developed for the drug internalization at diseased neurons and then minimize off-target effects. For example, neurons in cerebral cortex and hippocampus (affected by AD) highly 
express the M1 and M2 muscarinic acetylcholine receptors [29], while neurons in the striatum (affected by Parkinson's disease, PD) highly express M4 [30]. The use of the appropriate ligand will enable selective targeting of diseased neurons [1].

A non-invasive strategy to bypass the $\mathrm{BBB}$ and blood cerebrospinal-fluid barrier is the intranasal delivery of drugs. In this route of administration, drugs are transported from nose to central nervous system through the olfactory and trigeminal nerves. Current evidence suggests that the perineural and perivascular spaces of these two nerves play a prominent role in drug trafficking, even though drug can also be endocytosed and travel intracellularly [31]. The combination of targeting delivery systems with the intranasal application would maximize the chance of drugs reaching the specific site of action.

\subsection{Basement Membrane}

The vascular basement membrane is a three-dimensional protein network situated between brain capillaries and the supportive cells. This extracellular matrix is secreted by pericytes and endothelial cells. It is predominantly composed of fibronectin, $\alpha 4$ and $\alpha 5$ laminins, tenascin, type IV collagen, heparin sulphate proteoglycans, and other glycoproteins [32]. The function of this matrix is to provide mechanical support for cell migration and attachment, playing an important role in BBB development, stability, barrier integrity, and providing also physical separation of adjacent tissues. In the context of drug delivery, it has been considered that the physical properties of the vascular basement membrane are an important hurdle to the overpass.

\section{Nanoparticle-based delivery systems for neuronal targeting}

Nanomaterial based delivery approaches, which can be cooperatively termed as nanomedicines, have already been recognized as a competitive option of conventional therapies [33]. Nanomedicines, assembled from nanoscale materials ranging between one and several hundred nanometers, can load a variety of therapeutics including small molecule drugs, therapeutic proteins, genetic materials, and diagnosis modalities to deliver in the diseased site. With a unique pharmacokinetic/pharmacodynamic profile, nanomedicine delivers many pharmacological advantages over conventional therapy, such as improved bioavailability, reduced toxicity, and increased target-tissue selectivity. Today, nanomedicines are demonstrating significant potential in the clinics to treat a variety of severe health conditions, including cancers, infectious diseases, cardiac diseases, ocular diseases, and so on [34]. Although primarily in the preclinical stage, possibilities of using nanomedicine in the CNSrelated diseases have also been evaluated by many research groups [35]. The positive outcomes from nanomedicines in the treatment of many intractable diseases signify the persuasion of the nanomedicine-based approaches to overcome the extraordinary challenges of delivering therapeutic payloads to brain residing neurons. In this section, different types of nanomedicines (based on the structural characteristics, such as, size, shape and surface properties) (Table 2) and the main examples of in vivo efficiency on neuronal delivery, are discussed (Fig. 1).

\subsection{Lipid-based nanomedicines}

Liposomes, which are the most common lipid-based nanoparticles (LNPs), are vesicular drug delivery systems composed of natural and synthetic phospholipids, cholesterol, and other charged molecules, typically lipid derivatives [36]. Liposomes can entrap a variety of therapeutic entities, for example, small molecule drugs, biomacromolecules, and even inorganic materials inside its core that led to its versatile utility in drug delivery. Currently, several liposomal formulations are in the market and also many in the clinical trials for several diseases, including cancer, fungal and viral infections, pain management, genetic disorders, and other 
ailments [37,38]. Liposomal doxorubicin was the first such formulation to reach the market in 1995 for clinical use in sarcoma and ovarian cancer, with several research groups currently exploring its application to neuroblastoma [39], which suggests that LNPs can be used for delivering drugs to neurons as well.

Among other types of LNPs, lipoplexes and nanovesicle complexes are the ones composed of cationic lipids capable of forming ionic interactions with polyanions like nucleic acids [40,41]. Thus, they can be utilized as delivery agents for therapeutic pDNA, siRNA, mRNA, and antisense oligonucleotides (ASOs). Tagalakis et al. [42] reported the preparation method of giant unilamellar vesicles from cationic lipid and phospholipids (1:1 molar ratio) through the lipid film hydration method. The vesicles were transformed into nanovesicles by the modified water-in-oil (W/O) emulsion transfer method [43], where the emulsion was suspended in an intermediate phase - a biphasic system containing the lipids dissolved in mineral oil, and an aqueous glucose solution. After centrifugation, unilamellar vesicles will be formed. These nanovesicles were then mixed with targeting peptides, and DNA or siRNA producing nanocomplex formulations ranged from $90-140 \mathrm{~nm}$ with an encapsulation rate of $94 \%$. Fluorescent nanocomplexes were internalized in Neuro-2a cells and showed luciferase gene expression comparable to conventional cationic liposomes but with lower toxicity.

Neutral LNPs are also useful for mRNA and pDNA delivery to the cells [44]. These LNPs were prepared using tertiary amine-containing lipid derivatives that are neutral in the formulation, but upon endocytosis, the low $\mathrm{pH}$ inside the endosomes protonates these amines, decreasing their hydrophobicity and promoting collapse of the lipid nanoparticle. Tamaru et al. [45] delivered luciferase pDNA using this system into Neuro-2a and CAD cells. In another example, Tanaka et al. [46] delivered neutral LNP-encapsulated enhanced green fluorescent protein (eGFP) mRNA into the mouse brain. After intracerebroventricular (ICV) administration, gene expression was observed in brain tissue sections. Using MAP-2 as a neuronal marker, co-localization of the eGFP gene expression and MAP-2 was detected, indicating LNP uptake into neurons.

LNP-based strategy has been used for the delivery of ASOs, which have low brain accessibility, against CNS diseases. Aside from the use of liposomal methylprednisolone to modulate CNS inflammation [47], one promising target for the drug delivery approach is superoxide dismutase 1 (SOD1), which is mutated in motor neurons in familial amyotrophic lateral sclerosis (ALS) [48]. Chen et al. [49] loaded SOD1 ASO into calcium phosphate nanoparticles, and then encapsulated this complex into a lipid layer. This LNP has a solid inorganic/nucleic acid core enclosed in an inner layer of dioleoylphosphatidic acid (DOPA) and an outer layer of dioleoyl3-trimethylammonium propane (DOTAP), cholesterol, and DSPE-PEG 2000 (distearoylphosphoethanolamine- polyethylene glycol 2000) The system is pH-sensitive, displaying increased disassembly at $\mathrm{pH}$ 5. Fluorescence-labelled particles showed timedependent cell uptake into a neuron-like NSC-34 cell line, accumulating in the cytoplasm. SOD1 levels have also been successfully knocked-down in HEK-293T cells and distributed in the brain and labeled neurons in a zebrafish model.

Similar to ASO encapsulation, LNP-based strategies have been developed to encapsulate siRNA to treat neurodegenerative diseases. The use of a low molecular-weight branched polyethyleneimine (PEI) to form lipoplexes with siRNA [50] was able to reduce $\alpha$-synuclein (SNCA) mRNA and protein both in vitro and in vivo, as well as demonstrate neuronal uptake. In this study, PEI lipoplexes were administered through the ICV route. However, it is unclear whether this kind of formulation can survive intravenous (IV) administration since the positive charge may cause non-specific interactions with proteins in the bloodstream. Anionic liposomes 
seem to avoid this problem. Schlich et al. [51] first prepared polyplexes with anti-SNCA siRNA and protamine, a naturally occurring protein, and then encapsulated the whole particle into anionic stealth liposomes made of distearoylphosphatidylcholine (DSPC), cholesterol, and DSPE-PEG. The negatively-charged, phospholipid-rich layer is attracted to the positivelycharged polyplex, which stabilizes the particle. The surface was also decorated with rabies virus glycoprotein-derived (RVG) peptide because it imparts a BBB-crossing property to the liposome. Fluorescence-labelled LNPs showed strong signal co-localization with NeuNimmunopositive primary cortical and hippocampal cells in vitro. This data is corroborated by SNCA knockdown, confirming the entry of both the LNP and cargo in neurons.

\subsection{Polymeric nanomedicines}

Polymers are extensively utilized in drug delivery due to their many desirable properties, such as excellent biocompatibility, nontoxicity, feasible preparation, structural diversity, and controllable molecular architecture [52]. A variety of polymer-based therapeutics, such as polymeric drugs, polymer-drug conjugates, polymer-protein conjugates, dendrimers, polymeric micelles (PMs), and polyplexes, which can be collectively termed as polymer therapeutics, are used in a wide range of clinical applications, including cancer, autoimmune diseases, and neurological disorders [53]. An immunomodulatory polymeric drug glatiramer acetate (GA, Copaxone ${ }^{\circledR}$ ), used for relapsing-remitting multiple sclerosis (RRMS), has secured its position in the US top 10 selling drugs list [53]. Multiple sclerosis (MS) is a neurodegenerative disease of the CNS symptomatically categorized as immune-mediated damage of myelin, the protective coating on nerve fibers. GA is a random polymer of glutamic acid, lysine, tyrosine, and alanine, four amino acids that are found in myelin basic protein (MBP). The molecular mass of the constituent polypeptides of GA ranges from 4.7 to $11 \mathrm{kDa}$. The mechanism of action for GA against RRMS is complex and has not been entirely interpreted, but the structural similarity of GA to MBP may allow it to act in an immunomodulating and neuroprotective fashion [54]. In addition to GA, another polymer therapeutics, Peginterferon Beta-1a (PLEGRIDY ${ }^{\circledR}$ ), got FDA approval for the treatment of MS in 2014. The use of subcutaneous PEGylated (20 kDa molecular weight) interferon beta-1a offers an improved arrangement of pharmacokinetic and pharmacodynamic profiles and therapy-related side effects that leads to better patient compliance [55].

Aside from polymeric drugs and polymer drug-conjugates, PMs also exhibit high potential as nanomedicines, with various formulations under investigation in the preclinical and clinical phase for oncologic applications [56]. PMs prepared from amphiphilic block copolymers and spontaneous self-assembly processes manifest several attractive features as a preferred drug carrier. These features include a core-shell structure with the drug in the core (and thus adequately protected), a high drug loading capacity, an optimal size range of 10-100 nm in diameter and a prolonged blood circulation property, enabling tumour-specific preferential accumulation and penetration using the so-called enhanced permeability and retention (EPR) effect. The surface of polymer micelles could also be decorated with disease-specific ligands to increase its targeting ability and thus expand its therapeutic utility up until hard to reach cancers such as Glioblastoma Multiforme (GBM). GBM, the most lethal brain tumour, is nearly inaccessible to systemic therapy due to the presence of the blood-brain-tumour-barrier. Anticancer drug-loaded PMs, decorated with cyclic-Arg-Gly-Asp (cRGD) peptides that can target $\alpha v \beta 3$ - and $\alpha v \beta 5$-integrins overexpressed in neovasculature and GBM cells [57], achieved efficient drug delivery to GBM tumours via an active transcellular pathway, bringing significant antitumour effects in a mouse model of GBM $[58,59]$. 
292 In addition to the oncologic application, the potential use of PM-type nanomedicines in other 293 types of severe diseases, such as AD [60], sensory nerve disorders [61], and spinal cord injury 294 [62], has also been evaluated. In these cases, polyplex micelles, formulated by self-assembly of oppositely charged PEG-polycation block copolymers and mRNA, have been utilized [63]. The core-shell structure of polyplex micelles, having the mRNA-polyamine complex in the core that is efficiently shielded by the water-soluble PEG corona, offers protection of loaded mRNA against nuclease attack, immune recognition, and aggregation in biological milieus. Intranasal administration of brain-derived neurotrophic factor (BDNF)-expressing mRNA loaded polyplex micelles enhanced the neurological recovery of olfactory function along with repairing the olfactory epithelium to an approximately typical architecture in a mouse model of experimentally induced olfactory dysfunction [61].

Lin et al [60] prepared a polyplex-micelle based delivery system consisting of PEG-poly \{N-[N(2-aminoethyl)-2-aminoethyl]aspartamide\}, (PEG-PAsp(DET)) and neprylisin (NEP) mRNA. $\mathrm{NEP}$, a protease, degrades amyloid- $\beta$ (A $\beta$ ), excessive production of which leads to neuronal death in AD. In vitro, GFP-fused NEP was expressed in Neuro2A and mouse primary neurons. NEP activity was confirmed when the $A \beta$ introduced into the culture media was degraded. When the PMs were administered into C57/BL6J mice by ICV infusion, the GFP signals were found to co-localize with that of NeuN-marked neurons. Finally, the positive measurement of in vivo $\mathrm{A} \beta$ degradation verified that NEP mRNA can indeed be delivered into neurons in order to reduce concentrations of $A \beta$ in the brain.

\subsection{Inorganic nanomedicines}

Compared to organic NPs, inorganic NPs are considered to be more stable and are commonly used for diagnostics and implants [64] in addition to delivery systems. They have found niche uses in biomedicine because of their inherent ability to interact with radiation. Examples of inorganic NPs include iron oxide NPs (serve as MRI contrast agents), quantum dots (substitute for fluorescent dye-loaded NPs), and materials that exhibit localized surface plasmon resonance like gold nanoparticles (used in diagnostics and plasmonic photothermal therapy) $[65,66]$.

Due to their highly tuneable size, geometry, and surface functionality [67], the physicochemical properties of inorganic NPs can be easily modified, and the influence of these adaptable physicochemical characteristics on cell internalization and intracellular trafficking has been extensively studied against different types of cancer cells $[68,69]$. On the other hand, there are only a few literature reports investigating the effect of the size and shape of NPs on neurons [70]. Yet, Stojiljković et al. [71] conclusively demonstrated this when they measured the cellular uptake of gold nanoparticles (AuNPs) in differentiated (SHd) and undifferentiated (SHu) SH-SY5Y cells. AuNPs of different shapes (spheres and ovals) and sizes (15, 40, and 80 $\mathrm{nm}$ ) were prepared by reduction of gold (III) chloride using trisodium citrate. Different charges (anionic and cationic), as well as protein and lectin coatings, were introduced on the AuNP surface post-synthesis. Cellular uptake using epifluorescence and epipolarization microscopy revealed that $\mathrm{SHu}$ favoured the uptake of 15-nm AuNPs while 40-nm AuNPs preferentially internalized by SHd. Both cell types preferred cationic over anionic particles. SHd uptake was enhanced by coating with protein G or wheat germ agglutinin (WGA), while only protein G decoration increased uptake in SHu. While differentiation supposedly lowers mitotic activity and hence cell uptake of NPs [72], WGA recognizes the $N$-acetylglucosamine residues, which are abundant on the surface of SHd [73]. One of the critical features of AuNPs is its catalytic activity on the oxidation of nicotinamide adenine dinucleotide hydride (NADH) to the critical energetic co-factor, NAD+, which is an essential coenzyme involved in the production of ATP, 
the cellular energy source [74]. This critical feature of AuNPs has been utilized for the remyelination process in stable RMS therapy, as the myelin production is an energetically expensive process. Clean-surfaced, faceted gold nanocrystals (CNM-Au8) exhibited robust remyelinating activity with functionally-improved motor behaviours in mice following chronic exposure of the demyelinating agent, cuprizone, and acute exposure to another demyelinating agent lysolecithin. These gold nanocrystals function through a novel energy metabolism pathway, which involves enhancing key aerobic glycolysis indicators. A Phase 2, doubleblinded, randomized, placebo-controlled trial is currently underway in stable RMS due to encouraging preclinical results and the favourable safety/toxicity profiles obtained by CNMAu8 [75] (Table 1).

Spherical and rod-shaped fluorescent semiconductor nanocrystals, commonly known as quantum dots (QDs) or quantum rods (QRs), represents one of the most successful classes of fluorescence probes for bio-imaging facilitating investigation of intracellular processes at the single-molecule level and long-term in vivo inspection of cell trafficking, tumour targeting and diagnostics [76]. In an exciting research report, Malvindi et al., utilized asymmetric core-shell $\mathrm{CdSe} / \mathrm{CdS}$ rod-shaped nanocrystals to investigate neuronal stimulation on a freshwater coelenterate, Hydra vulgaris [77]. They suggested that this neuron stimulatory effect is exclusively shape-dependent as the spherical counterpart of QRs failed to deliver the same stimulation. QRs used in this study had an average length of $35 \mathrm{~nm}$ with a diameter of around 4 $\mathrm{nm}$, whereas the diameter of the core-shell spherical nanocrystals, the QDs, was around $24 \mathrm{~nm}$. While the local electric field associated with the permanent dipole moment of QRs was intense enough to induce tentacle writhing on $H$. vulgaris (which might have resulted from activation of neurons or nematocytes), the QDs with low internal dipole moment were unable to induce such neuronal sensory effect. In addition to shape, the surface charge of NPs also plays critical role on specific interaction of NPs with neurons. Utilizing CdSe/CdS QRs, Dante et al, demonstrated that negatively-charged NPs interact with the neuronal membrane, while NPs with a positive or neutral charge did not localize on neurons [78]. More intriguingly, this effect is independent of the size, shape, and material of NPs. Negatively-charged NPs swiftly get localized on neuronal membranes and instigate an electrophysiological alteration. On the other hand, NPs with positive or neutral zeta-potential shows negligible nonspecific interaction with the neuronal membrane and thus induce no effects on bioelectric activity.

In addition to AuNPs and $\mathrm{QR} / \mathrm{QD}$ nanocrystals, mesoporous silica nanoparticles (MSNs) are inorganic NPs with promising biomedical applications. MSN size and surface functionalization are easily modifiable, aside from exhibiting biocompatibility and low toxicity. The pores used for drug loading have tuneable volumes [79]. MSNs can be synthesized by in situ polymerizations of orthosilicic acid in the presence of a base and cetyltrimethylammonium bromide as a surfactant template. Tetraethylorthosilicate is commonly used as the silica source [80]. Zhang et al. [81] prepared dopamine (DA)-decorated MSNs to deliver GSH into dopaminergic neurons. Since cells like SH-SY5Y express the DA transporter and DA receptors 2 and 3 [82], DA can be used as a targeting ligand. MSNs with a rod-shaped mesoporous structure with dimensions of 180 and $120 \mathrm{~nm}$ were functionalized with DA through an isocyanate group on its surface. Confocal microscopy revealed increased cellular uptake of DAconjugated MSNs as compared to non-decorated MSNs. When non-dopaminergic HEK-293T cells were treated, non-specific uptake was not observed. Furthermore, pre-treatment of the cells with DA blocked the internalization of DA-conjugated MSNs, proving the concept of DApromoted uptake.

\subsection{Cell-derived nanomedicines-extracellular vesicles}


Major extracellular vesicles (EVs), which are lipid-bound membrane vesicles secreted by cells into the extracellular space, include exosomes, microvesicles, and apoptotic bodies. Exosomes, whose size ranges approximately $50-100 \mathrm{~nm}$ in diameter, are secreted by exocytosis of multivesicular bodies, which are essential intermediates in endolysosomal transport [83]. These vesicles facilitate intercellular communication by carrying biologically active molecules, which are essential for cellular function [84]. Examples of cargo are mRNA and miRNA [85], and their delivery mechanisms include direct contact between surface molecules of vesicles and cells, endocytosis of vesicles, and vesicle-cell membrane fusion [83].

In a report by Oszvald et al. [84], EVs were shown to contribute to the maintenance of the intestinal stem cell niche via the delivery of EGF family members that act as niche factors. Leoni et al. [86] and colleagues further report that Annexin A1 was released as an EV component derived from intestinal epithelial cells to activate wound repair circuits. Thus, patients with active inflammatory bowel disease had elevated levels of secreted Annexin A1containing EVs in sera, which indicate their systemic distribution in response to inflammation.

This alteration of exosome levels in diseased conditions can be employed in active-targeted nanomedicine. Targeting the brain by neuron-specific RVG peptide-modified exosomes has been investigated to facilitate the delivery of $\alpha$-synuclein-recognizing DNA aptamers into the mouse brain for PD [87]. In this technique, Lamp2b, the exosomal outer membrane protein, was engineered to fuse with the neuron-specific RVG peptide through its extra-exosomal Nterminus. These exosomes were prepared by transfecting HEK-293T cells with RVG-Lamp2b plasmids and then recovering the exosomes through gradient centrifugation. The DNA aptamers were loaded by complexation with PEI and then add to the exosomes, generating 100-nm bilayer-membraned vesicles. Fluorescent exosomes were shown to be internalized into Neuro2a cells. When administered intraperitoneally (IP), the particles were able to reach the mouse brain and decrease $\alpha$-synuclein aggregates in a mouse PD model. This is a prime example that surface modification of the EVs to target cells that have characteristic diseased states would be an efficient strategy in drug delivery.

Inorganic NP-exosome hybrids can also be prepared to take advantage of the exosomal surface for its pharmacokinetics [88]. In an important work by Perets et al [89], AuNPs were encapsulated inside bone marrow mesenchymal stem cell (MSC)-derived exosomes by incubating primary myoblasts with 5-nm AuNPs. AuNPs give the benefit of easily tracking the distribution of the MSC-derived exosomes. When administered intranasally to mice models of neurodegenerative diseases, the fluorescent exosomes gave signals which co-localized with that of NeuN-marked neurons in the pathological regions.

\subsection{Studies using passive or active neuronal targeting in CNS diseases}

Most significant limitations in the therapeutic management of neurological disorders relies on the chemical instability, poor pharmacokinetics, deficient entry of the drug into the brain, and toxicity associated to the action of the therapeutics on non-neuronal cells or in peripheral tissues [4]. Besides, even though some drugs can cross BBB, their therapeutic efficacy is still limited by the lack of specific uptake by the disease-associated neurons [1]. Therefore, there is an urgent need for developing therapeutic platforms for drug delivery to treat neurological diseases. In this context, recent advances in nanotechnology have allowed the development of nanomedicines overcoming BBB in neuronal pathologies and target specific regions in the brain $[1,4,10]$. 
Currently, there are only a few clinical trials using nanoparticles targeting neuronal diseases

(Table 1) and in these examples there is no evidence of neuronal uptake despite the therapeutic cargo provides pharmacological effects on neurons. Therefore, to improve clinical outcomes, in addition to bypassing BBB, targeting NPs against a specific population of brain cells is a major challenge. There are different approaches reported in the literature using NPs as drug-delivery system for the treatment of neuronal diseases and evidencing neuronal uptake (Fig. 1). A very common approach is loading the drug in a NP that can cross the BBB [9], by either choosing an adequate material or decorating the particle with a BBB-specific ligand, which will increase bioavailability in the brain [90]. Although not using neuron-specific ligands, this type of approach, is in some way demonstrating NP accumulation into neurons (e.g., by fluorescence microscopy) or assuming that the cargo has been released in the vicinity of the target cell by evidencing pharmacological improvement in neurons. This approach could be named as "passive neuron-targeted approaches" (Fig. 1). The most desirable and advanced strategy is the decoration of the NP with neuron-specific ligands (e.g., Tet1, RVG), thus improving the efficiency of the dose into neurons instead of other brain cell types and enhancing targeting to disease-associated neurons. These approaches using neuron-specific ligands evidence NP uptake in neurons and will be referred to as "active neuron-targeted approaches" (Fig. 1). Some of these nanoformulations could even target a specific population of neurons (Fig. 1). It is also important to highlight that, in order the bypass $\mathrm{BBB}$, in the last few years, intranasal administration of brain-targeting nanoformulations is gaining importance [91,92] (Fig. 1).

The present section of the review is focused on reporting the most promising in vivo studies based on passive or active neuron-targeted strategies with the highest clinical prospect.

\subsubsection{Passive neuron-targeted approaches}

This type of approach takes advantage of the remarkable characteristics of nanomedicines, such as increased circulation time and stability, in order to improve the chemical properties of drugs and, particularly, to boost BBB crossing and access brain cells [9]. Up to now, there are only a few examples used in humans (Table 1), and unfortunately these examples do not demonstrate specific uptake of the nanomedicine by neurons. Among these, the only clinically approved nanoformulations for neuron-related disorders are polymeric-based therapeutics indicated in the treatment of multiple sclerosis (Table 1) [53,55]. The other nanomedicines are currently under clinical trials, mainly recruiting patients for Phase 2 in case of CNM-Au8 and APH-1105 nanoparticles for $\mathrm{AD}, \mathrm{PD}$, amyotrophic lateral sclerosis, and multiple sclerosis (Table 1).

Apart from those clinical examples, most of the nanoformulations based on passive neurontargeted approaches are evaluated in preclinical investigations. They are mainly directed towards $\mathrm{AD}$ and $\mathrm{PD}$ therapy [2] and rely on the use of polymeric and lipid-based nanocarriers. In $\mathrm{AD}$, these nanomedicines have proven very useful to improve the pharmacological efficiency of drugs with low bioavailability in the brain, poor solubility, and chemical instability. In this sense, Sánchez-López et al. [93] have recently developed PEGylated poly(lactic-co-glycolic acid) (PLGA) nanoparticles loaded with memantine, an antagonist to NMDA receptors used to treat AD. Memantine blocks NMDA receptors, decreasing the excess of glutamate that causes neuronal death. However, its clinical relevance in $\mathrm{AD}$ is limited due to low access to the CNS. The authors found that a NP-based formulation of memantine increases its availability in the brain, and therefore increases its effectiveness against the disease in APP/PS1 transgenic mice [93].

The use of ASO therapies has recently revealed its potential for the treatment of CNS disorders such as AD [94]. ASOs can halt the progression of the disease by neuronal gene knockdown or 
splicing modulation. Despite their low accessibility [94], ASOs have been successfully delivered to the CNS in mice model by encapsulation in multiple glucose-installed nanocarriers capable of crossing the BBB, which can be bound to GLUT-1 expressed on brain capillary endothelial cells [95]. The controlled glucose density on the surface of the nanocarrier allows the regulation of its distribution within the brain, and it has been successfully optimized to increase the number of nanocarriers accumulating in neurons [96].

Brain-targeted nanosystem-based formulations can also be used to reduce toxicity and side effects of a drug by reducing the necessary dose. For instance, current strategies against PD are based on oral administration of dopaminergic drugs able to restore DA levels in specific areas of the brain. Nevertheless, the clinical use of these drugs relies on temporary effects with side effects, without overcoming the progression of the disease [97]. This is the case of levodopa, a precursor of DA, which is the standard treatment for PD. Polymeric NPs loaded with levodopa $[98,99]$ or DA [100] in rodent models of PD exhibited promising results in neurobehavioral abnormalities of parkinsonian animals without undesired cardiovascular and central effects already described with the free drug [101].

One of the most promising therapeutic tools for neurodegenerative diseases is neurotrophic factors. Unfortunately, the crucial problems for their clinical application are their very short half-life and poor BBB crossing ability [102]. In the last few years, NPs encapsulating neurotrophic factors have been revealed as the optimal carrier to overcome BBB, protect agents from degradation, and prolong their circulation half-life [2]. Encapsulation of neuroprotective peptides like NAP in PEG-polylactide (PLA) nanoparticles, modified with B6 peptide (a transferrin substitute) acting as a specific ligand for BBB crossing, evidenced an enhanced brain and neuron delivery of NAP in vitro and in vivo mice models of AD [103].

Nose-to-brain delivery is not only a promising administration way for nanoformulations of neurotrophic factors against neurodegenerative diseases but also for the delivery of clinically relevant drugs used in epilepsy [91]. Musumeci et al. [104] recently developed oxcarbazepine loaded PLGA nanoparticles for intranasal administration. Oxcarbazepine, although approved as a first-line treatment for focal seizures, shows several secondary effects associated to its high distribution after oral administration. Intranasal administration of oxcarbazepine loaded PLGA NPs enhanced brain targeting efficiency, reduced the number of administrations compared to the free drug controlling seizures, and induced neuroprotection in rats [104]. Therefore, nanomedicine-based approaches, including intranasal formulations, evidence their potential against epilepsy [91].

Although these passive-based approaches can be clinically relevant, they still importantly rely on the ability of other brain cells to non-specifically internalize the drug or the nanocarrier leading to undesired effects and low pharmacological efficiency.

\subsubsection{Active neuron-targeted approaches}

Cell-specific targeting is relevant to minimize off-target delivery and to improve the efficiency of the drug [24]. Since neuron-specific drug delivery is challenging, up to now, the number of neuron-targeted nanoformulations validated in vivo is still very low but with promising outcomes for clinical applications (Table 3). These strategies are normally based on the surface decoration of the nanocarriers with ligands expressed in neurons. Furthermore, some of these studies used a dual-targeting strategy based on co-decoration of both BBB-penetrating ligand and neuron-targeting ligand on the surface of the nanocarrier $[105,106]$. 
Tet1 is a 12-amino acid peptide that has been shown to bind specifically to neurons and et al. [107] recently developed PEGylated poly(2-(N,N-dimethylamino)ethylmethacrylate) (PEG-PDMAEMA) nanocomplexes decorated with cingulin (CGN) peptide for BBB crossing and the Tet1 peptide for neuron-specific binding. The nanocomplexes formed were loaded with BACE1 siRNA. BACE1 (beta-site amyloid protein precursor cleaving enzyme 1) is a key protein necessary for the formation of $\mathrm{A} \beta$ plaques in $\mathrm{AD}$. The use of this nanoformulation avoided siRNA degradation, achieved neuron targeting, and improved cognitive function and symptoms of AD in APP/PS1 transgenic mice [107]. A recent study from the same research group, updated this targeting strategy by developing a fusion peptide consisting on a BBBpenetrating TGN peptide (a peptide with higher brain accumulation than CGN) and a neuronbinding peptide Tet1, through a glycine linker to synergistically increase the BBB- and neuron targeting efficacy [106]. The TPL-NP was used for the encapsulation of NAP, which is a neuroprotective peptide whose clinical application is limited due to ineffective neuron targeting. Administration of TPL-NP loaded with NAP in AD mice significantly enhanced neuroprotection and improved cognitive performance [106].

A therapeutic target for $\mathrm{AD}$ management is oxidative damage in mitochondria of impaired central neurons. Therefore, the specific delivery of antioxidants, such as resveratrol, to the mitochondria of diseased neurons is a challenging issue for $\mathrm{AD}$ treatment. To tackle this problem, Yang et al. [108] elegantly achieved specific delivery of resveratrol by developing neuronal mitochondria-targeted micelles in PEG-PLA nanocarrier co-decorated with peptide $\mathrm{C} 3$, which is an NCAM mimicking peptide that serves both for brain and hippocampal neuron targeting, and triphenylphosphonium (TPP) that directs the micelle to the neuronal mitochondria. The targeted micelles into neuronal mitochondrial dysfunction achieved the restoration of cognitive function as well as improvement in other typical disease markers in APP/PS1 mice model. This is a promising and novel strategy to target neuronal mitochondria in $\mathrm{AD}$.

Another neuronal target to improve neuronal uptake of NPs is the tyrosine kinase receptor A (TrkA), which is overexpressed in more than $99 \%$ of neurons. For instance, Zhang et al. [109] developed a PEG NP modified with ApoA-1, to achieve BBB crossing by binding scavenger receptor B1, and with NL4, a peptide that simulates a nerve growth factor (NGF) domain and can bind TrkA in neurons. This NP was designed for the delivery of BACE1 siRNA in AD. The efficacy of this active neuronal targeting was first evaluated in vitro [109] and then in vivo in a mouse model of AD [110], indicating that this dual ligand combination is a promising strategy for targeting neurons in vivo. In line with this, Niu et al. [111] developed magnetic $\mathrm{Fe}_{3} \mathrm{O}_{4} \mathrm{NPs}$ functionalized with oleic acid for stabilization and decorated them with NGF, which targets the TrkA, and $N$-isopropylacrylamide acrylic acid (NIPAm-AA) adsorbed to SNCA shRNA. NIPAm-AA is a thermoresponsive, $\mathrm{pH}$-sensitive polymer, which is well-suited for drug delivery and controlled release. SNCA is a protein found in Lewy bodies, intracytoplasmic inclusions of aggregated protein that occur in PD and play an important role in the death of DA neurons in the substantia nigra. A therapeutic reduction of SNCA levels in the brain is therefore a potential target for a PD treatment. The authors demonstrated that these NPs are able to cross the BBB and target neurons to reduce SNCA expression both in vitro and in vivo [111].

Decoration of nanocarriers with lactoferrin has also been utilized for targeting diseased-neurons in PD [112,113]. Since the expression of the lactoferrin receptor is increased in dopaminergic neurons in the substantia nigra, IV administration of polymeric NPs loaded with GDNF [112] or 
565 urocortin [113] evidenced neuroprotection in a 6-hydroxydopamine-lesioned PD rat model. 566 However, the specific uptake of the drugs on a subtype of neurons was not reported.

567 The decorating ligand to target neurons may also be acting as a therapeutic drug. For instance, 568 corticotropin-releasing factor (CRF) is a neuropeptide involved in fear and anxiety by specific 569 activation of the $\mathrm{CRF}_{2}$ receptor. Central administration of antisauvagine-30, an antagonist of the $570 \mathrm{CRF}_{2}$ receptor, is promising in withdrawal anxiety [114]. Therefore, a nanoformulation based 571 on iron oxide functionalized with (3-aminopropyl)triethoxysilane, which can readily cross the 572 BBB, was decorated with antisauvagine-30 in order to act as a guiding peptide into the target 573 neurons and also as the delivered drug to ameliorate anxiety-like behaviour in rats [114].

574 The use of other ligands for specific neural cell targeting such as RVG peptides [25,26], or Ts1 575 [115] have also shown promising results. Nevertheless, these studies do not provide validations 576 in in vivo models of the disease, when BBB and neuron expression of markers are altered.

577 In addition to the use of surface ligands, brain- and neuron-targeted delivery could be also 578 achieved with the use of molecules acting as penetration enhancers to neurons. A recent 579 investigation found that in vivo co-administration of nanoliposomes with borneol elevated brain580 target efficiency in specific brain areas and particularly in neurons of cerebral cortex and 581 hippocampus bypassing astrocytes [116]. The authors described how the transport pathway of 582 borneol is providing the potential as a penetration enhancer and therefore improve neuron 583 targeting of nanoliposomes in specific brain cells.

584 Finally, exosomes are becoming a subject of interest in nanomedicine, due to their ability to 585 cross the BBB, target neurons and the possibility to load different cargos [27]. Perets et al. [89] 586 recently reported in an elegant study that MSC-derived exosomes were selectively uptaken by 587 neuronal cells, but not glial cells, in the pathological regions of brains from animal models of 588 CNS diseases such as AD. The migration and homing abilities of these exosomes toward 589 specific diseased neurons could be significantly influenced by inflammatory factors, attracting 590 the MSC-derived exosomes to lesioned areas. The authors combined AuNP labelling and CT 591 imaging for whole-brain tracking of the exosomes in the brain after intranasal administration. 592 This finding strengthens the possibility of using MSC-derived exosomes by intranasal 593 administration for targeted drug delivery in diseased neurons, though, to evaluate treatment 594 efficacy, future studies using the MSC-derived exosomes either with or without additional drug 595 cargo are needed.

\section{4. Conclusion and future perspectives}

597 In the previous sections, we have discussed several novel strategies that have been used in 598 recent years to enhance the neuron-specific targeting of nanomedicine for different neuronal599 related diseases. It should be noted that most of these studies are still in the pre-clinical stage. 600 The number of nanoformulations that are now used in humans to treat neurodegenerative 601 disorders is very low (Table 1), and they do not provide evidence for specific brain cell602 targeting. Recent publications presented in this review confirm the importance of neuronal603 targeting to treat CNS disorders in vivo, at least in pre-clinical models of these diseases. 604 Therefore, the progression and development of novel nanoformulations in this stage, 605 particularly the active neuron-targeted approaches, is crucial for its clinical impact in humans. 606 With this review, we reinforce the importance of brain cell-targeting against these diseases to 607 bridge the bench to the bedside gap.

608 The special pathophysiologic features of the CNS-related disorders that we elaborately 609 discussed earlier are one of the crucial factors for this sluggish clinical progress of 
nanomedicines in the CNS-area. However, from the fundamental research point of view, additional challenges for successful bench to bedside translation of nanomedicines for CNSdiseases arise, including: i) selection of a clinically relevant disease model, ii) confirmation of an administration pathway depending on the diseased area of the brain, iii) low toxicity of the nanomedicines in the healthy organs and brain areas, and finally iv) the delivery of relevant dosages of the cargo into the targeted neurons sparing the other brain cells. To overcome these challenges, many research groups are developing new nanomedicine-based approaches mainly focusing on achieving better BBB crossing and thereby therapeutic outcomes [117]. Additionally, an increasing number of studies are now developing strategies to reach neurons, even bypassing the BBB (i.e., nose-to-brain delivery) and fight against neuronal related diseases that are still unmet medical issues. In this case, the challenge is the delivery of therapeutic cargoes to brain residing neurons. Significant progress has been recently achieved for targeting neurons including the identification of the suitable nanomaterials or nanocarriers, the most appropriate BBB crossing ligands or brain delivery administration pathway and, as the biggest challenge, surface ligands able to lead the nanoformulation to a specific population of neurons, that is, an active neuron-targeted approach. In this sense, innovative strategies such as the use of dual-ligand fusion peptides to improve the brain-neuron targeting of polymeric nanocarriers [106] and development of neuronal mitochondria-targeted PMs [108] in vivo in AD, are examples of promising pre-clinical findings. Through these results, we may speculate it is only a matter of time before these active neuron-targeted approaches will be evaluated in clinical assays. In addition, the safety/toxicity profile of these nanoformulations is a crucial issue for the clinical application that is also being intensively investigated [118].

The positive outcomes prove the extraordinary ability and potential of nanomedicines for treating neuron-related pathologies in vivo, which will imply success on the clinical translation at the end. Functional collaborations between neurobiologists, materials scientists and chemists would enable a better understanding of this interdisciplinary field of "nanomedicine for neuron targeting" to identify novel targeting approaches and integrating these into nanomedicine platforms that will lead to promising and safe nanomedicine-based strategies able to reach the clinic and to overcome CNS diseases in the coming years.

\section{References}

Papers of special note have been highlighted as: $\bullet$ of interest; $\bullet \bullet$ of considerable interest

1. Zhang F, Lin YA, Kannan S, Kannan RM. Targeting specific cells in the brain with nanomedicines for CNS therapies. J. Control. Release. 240, 212-226 (2016).

•• Provides guidelines for the desing of brain cell-specific targeting nanoformulations considering the functions of CNS cell types in pathological conditions.

2. Hernando S, Gartziandia O, Herran E, Pedraz JL, Igartua M, Hernandez RM. Advances in nanomedicine for the treatment of Alzheimer's and Parkinson's diseases. Nanomedicine. 11(10), 1267-1285 (2016).

3. Babazadeh A, Vahed FM, Jafari SM. Nanocarrier-mediated brain delivery of bioactives for treatment/prevention of neurodegenerative diseases. J. Control. Release. 321, 211221 (2020).

4. Kang YJ, Cutler EG, Cho H. Therapeutic nanoplatforms and delivery strategies for neurological disorders. Nano Converg. 5(1), 35 (2018).

5. Harilal S, Jose J, Parambi DGT, et al. Advancements in nanotherapeutics for Alzheimer's disease: current perspectives. J. Pharm. Pharmacol. 71(9), 1370-1383 (2019). 
6. Yavarpour-Bali H, Ghasemi-Kasman M, Pirzadeh M. Curcumin-loaded nanoparticles: a novel therapeutic strategy in treatment of central nervous system disorders. Int. J. Nanomedicine. 14, 4449-4460 (2019).

7. Singh AP, Biswas A, Shukla A, Maiti P. Targeted therapy in chronic diseases using nanomaterial-based drug delivery vehicles. Signal Transduct. Target. Ther. 4(1), 33 (2019).

8. Kreuter J. Drug delivery to the central nervous system by polymeric nanoparticles: What do we know? Adv. Drug Deliv. Rev. 71, 2-14 (2014).

9. Xie J, Shen Z, Anraku Y, Kataoka K, Chen X. Nanomaterial-based blood-brain-barrier (BBB) crossing strategies. Biomaterials. 224, 119491 (2019).

10. Saraiva C, Praça C, Ferreira R, Santos T, Ferreira L, Bernardino L. Nanoparticlemediated brain drug delivery: Overcoming blood-brain barrier to treat neurodegenerative diseases. J. Control. Release. 235, 34-47 (2016).

11. Correale J, Villa A. Cellular Elements of the Blood-Brain Barrier. Neurochem. Res. 34(12), 2067-2077 (2009).

12. Persidsky Y, Ramirez SH, Haorah J, Kanmogne GD. Blood-brain Barrier: Structural Components and Function Under Physiologic and Pathologic Conditions. $J$. Neuroimmune Pharmacol. 1(3), 223-236 (2006).

13. Daneman R, Prat A. The Blood-Brain Barrier. Cold Spring Harb. Perspect. Biol. 7(1), a020412 (2015).

14. Krol S. Challenges in drug delivery to the brain: Nature is against us. J. Control. Release. 164(2), 145-155 (2012).

15. Patel MM, Patel BM. Crossing the Blood-Brain Barrier: Recent Advances in Drug Delivery to the Brain. CNS Drugs. 31(2), 109-133 (2017).

16. Cannon RE, Peart JC, Hawkins BT, Campos CR, Miller DS. Targeting blood-brain barrier sphingolipid signaling reduces basal P-glycoprotein activity and improves drug delivery to the brain. Proc. Natl. Acad. Sci. 109(39), 15930-15935 (2012).

17. Batrakova E V., Li S, Li Y, Alakhov VY, Kabanov A V. Effect of Pluronic P85 on ATPase Activity of Drug Efflux Transporters. Pharm. Res. 21(12), 2226-2233 (2004).

18. Abbott NJ, Rönnbäck L, Hansson E. Astrocyte-endothelial interactions at the bloodbrain barrier. Nat. Rev. Neurosci. 7(1), 41-53 (2006).

19. Colgan OC, Collins NT, Ferguson G, et al. Influence of basolateral condition on the regulation of brain microvascular endothelial tight junction properties and barrier function. Brain Res. 1193, 84-92 (2008).

20. Gurnik S, Devraj K, Macas J, et al. Angiopoietin-2-induced blood-brain barrier compromise and increased stroke size are rescued by VE-PTP-dependent restoration of Tie2 signaling. Acta Neuropathol. 131(5), 753-773 (2016).

21. Hall CN, Reynell C, Gesslein B, et al. Capillary pericytes regulate cerebral blood flow in health and disease. Nature. 508(7494), 55-60 (2014).

22. Armulik A, Genové G, Mäe M, et al. Pericytes regulate the blood-brain barrier. Nature. 468(7323), 557-561 (2010).

23. Rungta RL, Choi HB, Lin PJ, et al. Lipid Nanoparticle Delivery of siRNA to Silence Neuronal Gene Expression in the Brain. Mol. Ther. Nucleic Acids. 2(11), e136 (2013).

24. Kwon EJ, Lasiene J, Jacobson BE, Park I-K, Horner PJ, Pun SH. Targeted nonviral delivery vehicles to neural progenitor cells in the mouse subventricular zone.

Biomaterials. 31(8), 2417-2424 (2010). 
25. Huey R, O’Hagan B, McCarron P, Hawthorne S. Targeted drug delivery system to neural cells utilizes the nicotinic acetylcholine receptor. Int. J. Pharm. 525(1), 12-20 (2017).

26. Huey R, Hawthorne S, McCarron P. The potential use of rabies virus glycoproteinderived peptides to facilitate drug delivery into the central nervous system: a mini review. J. Drug Target. 25(5), 379-385 (2017).

27. Rufino-Ramos D, Albuquerque PR, Carmona V, Perfeito R, Nobre RJ, Pereira de Almeida L. Extracellular vesicles: Novel promising delivery systems for therapy of brain diseases. J. Control. Release. 262, 247-258 (2017).

28. Chivet M, Javalet C, Laulagnier K, Blot B, Hemming FJ, Sadoul R. Exosomes secreted by cortical neurons upon glutamatergic synapse activation specifically interact with neurons. J. Extracell. Vesicles. 3(1), 24722 (2014).

29. Fisher A. Cholinergic modulation of amyloid precursor protein processing with emphasis on M1 muscarinic receptor: perspectives and challenges in treatment of Alzheimer's disease. J. Neurochem. 120, 22-33 (2012).

30. Ztaou S, Maurice N, Camon J, et al. Involvement of Striatal Cholinergic Interneurons and M1 and M4 Muscarinic Receptors in Motor Symptoms of Parkinson's Disease. $J$. Neurosci. 36(35), 9161-9172 (2016).

31. Crowe TP, Greenlee MHW, Kanthasamy AG, Hsu WH. Mechanism of intranasal drug delivery directly to the brain. Life Sci. 195, 44-52 (2018).

32. Thomsen MS, Routhe LJ, Moos T. The vascular basement membrane in the healthy and pathological brain. J. Cereb. Blood Flow Metab. 37(10), 3300-3317 (2017).

33. Quader S, Kataoka K. Nanomaterial-Enabled Cancer Therapy. Mol. Ther. 25(7), 15011513 (2017).

34. Farjadian F, Ghasemi A, Gohari O, Roointan A, Karimi M, Hamblin MR. Nanopharmaceuticals and nanomedicines currently on the market: Challenges and opportunities. Nanomedicine. 14(1), 93-126 (2019).

35. Soni S, Ruhela RK, Medhi B. Nanomedicine in central nervous system (CNS) disorders: A present and future prospective. Adv. Pharm. Bull. 6(3), 319-335 (2016).

•• Emphasizes the use of nanomedicines in the CNS with special focus on BBB crossing strategies using lipid and polymeric nanoparticles and neuronal toxicity.

36. Zumbuehl O, Weder HG. Liposomes of controllable size in the range of 40 to $180 \mathrm{~nm}$ by defined dialysis of lipid/detergent mixed micelles. BBA - Biomembr. 640(1), 252-262 (1981).

37. Bulbake U, Doppalapudi S, Kommineni N, Khan W. Liposomal formulations in clinical use: An updated review. Pharmaceutics. 9(2), 1-33 (2017).

38. Kulkarni JA, Cullis PR, Van Der Meel R. Lipid Nanoparticles Enabling Gene Therapies: From Concepts to Clinical Utility. Nucleic Acid Ther. 28(3), 146-157 (2018).

39. Pastorino F, Brignole C, Di Paolo D, et al. Overcoming Biological Barriers in Neuroblastoma Therapy: The Vascular Targeting Approach with Liposomal Drug Nanocarriers. Small. 15(10), 1-13 (2019).

40. Zhang XX, McIntosh TJ, Grinstaff MW. Functional lipids and lipoplexes for improved gene delivery. Biochimie. 94(1), 42-58 (2012).

41. Tros de Ilarduya C, Sun Y, Düzgüneş N. Gene delivery by lipoplexes and polyplexes. Eur. J. Pharm. Sci. 40(3), 159-170 (2010).

42. Tagalakis AD, Maeshima R, Yu-Wai-Man C, et al. Peptide and nucleic acid-directed 
self-assembly of cationic nanovehicles through giant unilamellar vesicle modification: Targetable nanocomplexes for in vivo nucleic acid delivery. Acta Biomater. 51(January), 351-362 (2017).

43. Pautot S, Frisken BJ, Weitz DA. Engineering asymmetric vesicles. Proc. Natl. Acad. Sci. U.S. A. 100(19), 10718-10721 (2003).

44. Sato Y, Sakurai Y, Kajimoto K, et al. Innovative Technologies in Nanomedicines: From Passive Targeting to Active Targeting/From Controlled Pharmacokinetics to Controlled Intracellular Pharmacokinetics. Macromol. Biosci. 17(1), 1600179 (2017).

45. Tamaru M, Akita H, Nakatani T, et al. Application of apolipoprotein E-modified liposomal nanoparticles as a carrier for delivering DNA and nucleic acid in the brain. Int. J. Nanomedicine. 9, 4267-4276 (2014).

46. Tanaka H, Nakatani T, Furihata T, et al. In Vivo Introduction of mRNA Encapsulated in Lipid Nanoparticles to Brain Neuronal Cells and Astrocytes via Intracerebroventricular Administration. Mol. Pharm. 15(5), 2060-2067 (2018).

47. Evans MC, Gaillard PJ, de Boer M, et al. CNS-targeted glucocorticoid reduces pathology in mouse model of amyotrophic lateral sclerosis. Acta Neuropathol. Commun. 2(1), 1-13 (2014).

48. McCampbell A, Cole T, Wegener AJ, et al. Antisense oligonucleotides extend survival and reverse decrement in muscle response in ALS models. J. Clin. Invest. 128(8), 35583567 (2018).

49. Chen L, Watson C, Morsch M, et al. Improving the delivery of SOD1 antisense oligonucleotides to motor neurons using calcium phosphate-lipid nanoparticle. Front. Neurosci. 11(AUG), 1-12 (2017).

50. Helmschrodt C, Höbel S, Schöniger S, et al. Polyethylenimine Nanoparticle-Mediated siRNA Delivery to Reduce $\alpha$-Synuclein Expression in a Model of Parkinson's Disease. Mol. Ther. - Nucleic Acids. 9(December), 57-68 (2017).

51. Schlich M, Longhena F, Faustini G, et al. Anionic liposomes for small interfering ribonucleic acid (siRNA) delivery to primary neuronal cells: Evaluation of alphasynuclein knockdown efficacy. Nano Res. 10(10), 3496-3508 (2017).

52. Liechty WB, Kryscio DR, Slaughter B V., Peppas NA. Polymers for Drug Delivery Systems. Annu. Rev. Chem. Biomol. Eng. 1(1), 149-173 (2010).

53. Duncan R, Vicent MJ. Polymer therapeutics-prospects for 21st century: The end of the beginning. Adv. Drug Deliv. Rev. 65(1), 60-70 (2013).

- Highlights the optimal characteristics of polymeric-based nanocarriers opening new opportunities for design and clinical use of polymer-based therapeutics in the decades to come. Reference to the polymeric-based nanomedicine, Copaxone ${ }^{\circledR}$, the first nanoformulation approved to treat neurological disorders.

54. Weinstock-Guttman B, Nair K V., Glajch JL, Ganguly TC, Kantor D. Two decades of glatiramer acetate: From initial discovery to the current development of generics. $J$. Neurol. Sci. 376, 255-259 (2017).

55. Kolb-Mäurer A, Sunderkötter C, Kukowski B, Meuth SG. An update on Peginterferon beta-1a Management in Multiple Sclerosis: results from an interdisciplinary Board of German and Austrian Neurologists and dermatologists. BMC Neurol. 19(1), 130 (2019).

56. Cabral H, Miyata K, Osada K, Kataoka K. Block Copolymer Micelles in Nanomedicine Applications. Chem. Rev. 118(14), 6844-6892 (2018).

57. Mattern R-H, Read SB, Pierschbacher MD, Sze C-I, Eliceiri BP, Kruse CA. Glioma cell integrin expression and their interactions with integrin antagonists: Research Article. 
58. Miura Y, Takenaka T, Toh K, et al. Cyclic RGD-linked polymeric micelles for targeted delivery of platinum anticancer drugs to glioblastoma through the blood-brain tumor barrier. ACS Nano. 7(10), 8583-8592 (2013).

59. Quader S, Liu X, Chen Y, et al. cRGD peptide-installed epirubicin-loaded polymeric micelles for effective targeted therapy against brain tumors. J. Control. Release. 258, 56-66 (2017).

60. Lin CY, Perche F, Ikegami M, Uchida S, Kataoka K, Itaka K. Messenger RNA-based therapeutics for brain diseases: An animal study for augmenting clearance of betaamyloid by intracerebral administration of neprilysin mRNA loaded in polyplex nanomicelles. J. Control. Release. 235, 268-275 (2016).

61. Baba M, Itaka K, Kondo K, Yamasoba T, Kataoka K. Treatment of neurological disorders by introducing mRNA in vivo using polyplex nanomicelles. J. Control. Release. 201, 41-48 (2015).

62. Crowley ST, Fukushima Y, Uchida S, Kataoka K, Itaka K. Enhancement of Motor Function Recovery after Spinal Cord Injury in Mice by Delivery of Brain-Derived Neurotrophic Factor mRNA. Mol. Ther. - Nucleic Acids. 17, 465-476 (2019).

63. Uchida S, Kataoka K. Design concepts of polyplex micelles for in vivo therapeutic delivery of plasmid DNA and messenger RNA. J. Biomed. Mater. Res. Part A. 107(5), 978-990 (2019).

64. Sharma CP. Biointegration of medical implant materials : science and design. CRC Press, 1-412 (2010).

65. Giner-Casares JJ, Henriksen-Lacey M, Coronado-Puchau M, Liz-Marzán LM. Inorganic nanoparticles for biomedicine: Where materials scientists meet medical research. Mater. Today. 19(1), 19-28 (2016).

66. Paraiso WKD, Tanaka H, Sato Y, et al. Preparation of envelope-type lipid nanoparticles containing gold nanorods for photothermal cancer therapy. Colloids Surfaces B Biointerfaces. 160, 715-723 (2017).

67. Li W, Cao Z, Liu R, et al. AuNPs as an important inorganic nanoparticle applied in drug carrier systems. Artif. Cells, Nanomedicine Biotechnol. 47(1), 4222-4233 (2019).

68. Albanese A, Tang PS, Chan WCW. The Effect of Nanoparticle Size, Shape, and Surface Chemistry on Biological Systems. Annu. Rev. Biomed. Eng. 14(1), 1-16 (2012).

69. Zhang S, Gao H, Bao G. Physical Principles of Nanoparticle Cellular Endocytosis. ACS Nano. 9(9), 8655-8671 (2015).

70. Villanueva-Flores F, Castro-Lugo A, Ramírez OT, Palomares LA. Understanding cellular interactions with nanomaterials: towards a rational design of medical nanodevices. Nanotechnology. 31(13), 132002 (2020).

71. Stojiljković A, Kuehni-Boghenbor K, Gaschen V, et al. High-content analysis of factors affecting gold nanoparticle uptake by neuronal and microglial cells in culture. Nanoscale. 8(37), 16650-16661 (2016).

- Demonstrates crucial factors determining brain cellular uptake of gold nanoparticles. These are one of the nanoparticle types with higher potential to target neurons in neurological diseases in humans

72. Kim JA, Aberg C, Salvati A, Dawson KA. Role of cell cycle on the cellular uptake and dilution of nanoparticles in a cell population. Nat. Nanotechnol. 7(1), 62-68 (2012).

73. Kitamura N, Ikekita M, Hayakawa S, Funahashi H, Furukawa K. Suppression of Proliferation and Neurite Extension of Human Neuroblastoma SH-SY5Y Cells on 
Immobilized Psathyrella velutina Lectin. J. Neurosci. Res. 75(3), 384-390 (2004).

74. Huang X, El-Sayed IH, Yi X, El-Sayed MA. Gold nanoparticles: Catalyst for the oxidation of NADH to NAD+. J. Photochem. Photobiol. B Biol. 81(2), 76-83 (2005).

75. Robinson AP, Zhang JZ, Titus HE, et al. Nanocatalytic activity of clean-surfaced, faceted nanocrystalline gold enhances remyelination in animal models of multiple sclerosis. Sci. Rep. 10(1), 1-16 (2020).

76. Fu A, Gu W, Boussert B, et al. Semiconductor quantum rods as single molecule fluorescent biological labels. Nano Lett. 7(1), 179-182 (2007).

77. Malvindi MA, Carbone L, Quarta A, et al. Rod-Shaped Nanocrystals Elicit Neuronal Activity In Vivo. Small. 4(10), 1747-1755 (2008).

78. Dante S, Petrelli A, Petrini EM, et al. Selective Targeting of Neurons with Inorganic Nanoparticles: Revealing the Crucial Role of Nanoparticle Surface Charge. ACS Nano. 11(7), 6630-6640 (2017).

79. Mamaeva V, Sahlgren C, Lindén M. Mesoporous silica nanoparticles in medicineRecent advances. Adv. Drug Deliv. Rev. 65(5), 689-702 (2013).

80. Trewyn BG, Slowing II, Giri S, Chen H-T, Lin VS-Y. Synthesis and Functionalization of a Mesoporous Silica Nanoparticle Based on the Sol-Gel Process and Applications in Controlled Release. Acc. Chem. Res. 40(9), 846-853 (2007).

81. Zhang $\mathrm{H}$, Jiang $\mathrm{Y}$, Zhao SG, et al. Selective neuronal targeting, protection and signaling network analysis via dopamine-mediated mesoporous silica nanoparticles. Med Chem Comm. 6(6), 1117-1129 (2015).

82. Kovalevich J, Langford D. Considerations for the use of SH-SY5Y neuroblastoma cells in neurobiology. Methods Mol. Biol. 1078, 9-21 (2013).

83. György B, Szabó TG, Pásztói M, et al. Membrane vesicles, current state-of-the-art: Emerging role of extracellular vesicles. Cell. Mol. Life Sci. 68(16), 2667-2688 (2011).

84. Oszvald Á, Szvicsek Z, Sándor GO, et al. Extracellular vesicles transmit epithelial growth factor activity in the intestinal stem cell niche. Stem Cells. 38(2), 291-300 (2020).

85. Valadi H, Ekström K, Bossios A, Sjöstrand M, Lee JJ, Lötvall JO. Exosome-mediated transfer of mRNAs and microRNAs is a novel mechanism of genetic exchange between cells. Nat. Cell Biol. 9(6), 654-659 (2007).

86. Leoni G, Neumann PA, Kamaly N, et al. Annexin A1'containing extracellular vesicles and polymeric nanoparticles promote epithelial wound repair. J. Clin. Invest. 125(3), 1215-1227 (2015).

87. Ren X, Zhao Y, Xue F, et al. Exosomal DNA Aptamer Targeting $\alpha$-Synuclein Aggregates Reduced Neuropathological Deficits in a Mouse Parkinson's Disease Model. Mol. Ther. - Nucleic Acids. 17, 726-740 (2019).

88. Khongkow M, Yata T, Boonrungsiman S, Ruktanonchai UR, Graham D, Namdee K. Surface modification of gold nanoparticles with neuron-targeted exosome for enhanced blood-brain barrier penetration. Sci. Rep. 9(1), 1-9 (2019).

89. Perets N, Betzer O, Shapira R, et al. Golden Exosomes Selectively Target Brain Pathologies in Neurodegenerative and Neurodevelopmental Disorders. Nano Lett. 19(6), 3422-3431 (2019).

- Demonstrates an innovative approach with clinical perspective based on the use of golden exosomes derived from mesenchimal stem cells for selective neuronal targeting in lesioned areas after intranasal administration to animal models of neurological diseases. 
90. Wang B, Galliford C V., Low PS. Guiding principles in the design of ligand-targeted nanomedicines. Nanomedicine. 9(2), 313-330 (2014).

91. Musumeci T, Bonaccorso A, Puglisi G. Epilepsy Disease and Nose-to-Brain Delivery of 892 Polymeric Nanoparticles: An Overview. Pharmaceutics. 11(3), 118 (2019).

92. Khan AR, Liu M, Khan MW, Zhai G. Progress in brain targeting drug delivery system by nasal route. J. Control. Release. 268(September), 364-389 (2017).

93. Sánchez-López E, Ettcheto M, Egea MA, et al. Memantine loaded PLGA PEGylated nanoparticles for Alzheimer's disease: in vitro and in vivo characterization. $J$. Nanobiotechnology. 16(1), 32 (2018).

94. Rinaldi C, Wood MJA. Antisense oligonucleotides: the next frontier for treatment of neurological disorders. Nat. Rev. Neurol. 14(1), 9-21 (2018).

95. Min HS, KIM HJ, Naito M, et al. Systemic Brain Delivery of Antisense Oligonucleotides across the Blood-Brain Barrier with a Glucose-Installed Polymeric Nanocarrier. Angew. Chemie Int. Ed. (2020).

96. Anraku Y, Kuwahara H, Fukusato Y, et al. Glycaemic control boosts glucosylated nanocarrier crossing the BBB into the brain. Nat. Commun. 8(1), 1001 (2017).

97. Morin N, Jourdain VA, Di Paolo T. Modeling dyskinesia in animal models of Parkinson disease. Exp. Neurol. 256, 105-116 (2014).

98. Li X, Liu Q, Zhu D, Che Y, Feng X. Preparation of levodopa-loaded crystalsomes through thermally induced crystallization reverses functional deficits in Parkinsonian mice. Biomater. Sci. 7(4), 1623-1631 (2019).

99. Sharma S, Lohan S, Murthy RSR. Formulation and characterization of intranasal mucoadhesive nanoparticulates and thermo-reversible gel of levodopa for brain delivery. Drug Dev. Ind. Pharm. 40(7), 869-878 (2014).

100. Pahuja R, Seth K, Shukla A, et al. Trans-Blood Brain Barrier Delivery of DopamineLoaded Nanoparticles Reverses Functional Deficits in Parkinsonian Rats. ACS Nano. 9(5), 4850-4871 (2015).

101. Lafuente JV, Requejo C, Ugedo L. Nanodelivery of therapeutic agents in Parkinson's disease. In: Progress in brain research, 263-279 (2019).

102. Adessi C, Soto C. Converting a Peptide into a Drug: Strategies to Improve Stability and Bioavailability. Curr. Med. Chem. 9(9), 963-978 (2002).

103. Liu Z, Gao X, Kang T, et al. B6 peptide-modified PEG-PLA nanoparticles for enhanced brain delivery of neuroprotective peptide. Bioconjug. Chem. 24(6), 997-1007 (2013).

104. Musumeci T, Serapide MF, Pellitteri R, et al. Oxcarbazepine free or loaded PLGA nanoparticles as effective intranasal approach to control epileptic seizures in rodents. Eur. J. Pharm. Biopharm. 133, 309-320 (2018).

105. Zheng X, Zhang C, Guo Q, et al. Dual-functional nanoparticles for precise drug delivery to Alzheimer's disease lesions: Targeting mechanisms, pharmacodynamics and safety. Int. J. Pharm. 525(1), 237-248 (2017).

106. Guo Q, Xu S, Yang P, et al. A dual-ligand fusion peptide improves the brain-neuron targeting of nanocarriers in Alzheimer's disease mice. J. Control. Release. 320, 347-362 (2020).

- Demonstrates a promising strategy for neuronal targeting by using a dual targeting approach based on co-decoration of both BBB-penetrating ligand and neuron-targeting ligand on the surface of polymeric nanocarriers in animal models of Alzheimer's disease.

107. Wang P, Zheng X, Guo Q, et al. Systemic delivery of BACE1 siRNA through neuron- 
targeted nanocomplexes for treatment of Alzheimer's disease. J. Control. Release. 279, 220-233 (2018).

108. Yang P, Sheng D, Guo Q, et al. Neuronal mitochondria-targeted micelles relieving oxidative stress for delayed progression of Alzheimer's disease. Biomaterials. 238 (2020).

109. Zhang C, Gu Z, Shen L, Liu X, Lin H. A Dual Targeting Drug Delivery System for Penetrating Blood-Brain Barrier and Selectively Delivering siRNA to Neurons for Alzheimer's Disease Treatment. Curr. Pharm. Biotechnol. 18(14), 1124-1131 (2017).

110. Zhang C, Gu Z, Shen L, Liu X, Lin H. In vivo Evaluation and Alzheimer's Disease Treatment Outcome of siRNA Loaded Dual Targeting Drug Delivery System. Curr. Pharm. Biotechnol. 20(1), 56-62 (2019).

111. Niu S, Zhang L-K, Zhang L, et al. Inhibition by Multifunctional Magnetic Nanoparticles Loaded with Alpha-Synuclein RNAi Plasmid in a Parkinson's Disease Model. Theranostics. 7(2), 344-356 (2017).

112. Huang R, Han L, Li J, et al. Neuroprotection in a 6-hydroxydopamine-lesioned Parkinson model using lactoferrin-modified nanoparticles. J. Gene Med. 11(9), 754-763 (2009).

113. Hu K, Shi Y, Jiang W, Han J, Huang S, Jiang X. Lactoferrin conjugated PEG-PLGA nanoparticles for brain delivery: Preparation, characterization and efficacy in Parkinson's disease. Int. J. Pharm. 415(1-2), 273-283 (2011).

114. Vinzant N, Scholl JL, Wu C-M, Kindle T, Koodali R, Forster GL. Iron Oxide Nanoparticle Delivery of Peptides to the Brain: Reversal of Anxiety during Drug Withdrawal. Front. Neurosci. 11, 608 (2017).

115. Carvalho-de-Souza JL, Treger JS, Dang B, Kent SBH, Pepperberg DR, Bezanilla F. Photosensitivity of Neurons Enabled by Cell-Targeted Gold Nanoparticles. Neuron. 86(1), 207-217 (2015).

116. Wu Y, Wang S, Shang L, et al. Effect of borneol as a penetration enhancer on brain targeting of nanoliposomes: Facilitate direct delivery to neurons. Nanomedicine. 13(21), 2709-2727 (2018).

117. Teleanu DM, Negut I, Grumezescu V, Grumezescu AM, Teleanu RI. Nanomaterials for drug delivery to the central nervous system. Nanomaterials. 9(3) (2019).

118. Carro CE, Pilozzi AR, Huang X. Nanoneurotoxicity and Potential Nanotheranostics for Alzheimer's Disease. EC Pharmacol. Toxicol. 7(12), 1-7 (2019).

119. Cummings J, Lee G, Ritter A, Sabbagh M, Zhong K. Alzheimer's disease drug development pipeline: 2019. Alzheimer's Dement. Transl. Res. Clin. Interv. 5, 272-293 (2019).

120. Dolati S, Ahmadi M, Aghebti-Maleki L, et al. Nanocurcumin is a potential novel therapy for multiple sclerosis by influencing inflammatory mediators. Pharmacol. Reports. 70(6), 1158-1167 (2018).

121. Ahmadi M, Agah E, Nafissi S, et al. Safety and efficacy of nanocurcumin as add-on therapy to riluzole in patients with amyotrophic lateral sclerosis: A pilot randomized clinical trial. Neurotherapeutics. 15(2), 430-438 (2018). 


\section{$978 \quad$ Figure captions}

979 Figure 1. Approaches for the targeted delivery of therapeutics to diseased neurons. Brain access 980 of the nanomedicines depends on systemic or intranasal administration. The latter pathway 981 bypasses the Blood-Brain Barrier (BBB). Once inside the brain, if the nanoformulations are not 982 using neuron-specific ligands but evidence release of the drug into neurons or their vicinity, in 983 addition to other brain cells, it is referred to as "passive neuron-targeted approaches". The most 984 desirable strategy is the decoration of the nanoparticles with neuron-specific ligands thereby 985 reaching neurons instead of other brain types, the so-called "active neuron-targeted 986 approaches", which could be non-specific or specific for a neuronal sub-population. 
987

988

989

990

991

992

993

994

995

996

997

998

999

1000

1001

1002

1003

1004

1005

1006

1007

1008

1009

1010

1011

1012

1013

1014

1015

1016

1017

1018

\section{Executive Summary}

\section{Background}

- Neuron-related diseases are not adequately treated due to the lack of approaches to effectively reach the targets on specific neuronal populations.

- Nanomedicine-based approaches provide promising opportunities for overcoming these limitations and improving the therapeutic efficacy of central nervous diseases.

- Targeting neuronal cells in central nervous diseases is now one of the biggest challenges in both the nanomedicine and neuroscience field.

\section{Nanomedicines for neuronal targeting}

- Nanomedicines, including lipid-based, polymeric, inorganic nanoparticles, and exosomes, have experienced considerable advances in design and development to treat neuronal disorders.

- Only a few nanomedicines are currently being used in humans for treating neuronal diseases. However these examples do not specifically demonstrate neuronal uptake even though the therapeutic cargo provides pharmacological effects on neurons.

- Towards the process of improving clinical outcomes, the development of nanoformulations targeting a specific population of brain cells in vivo is in progress with promising results that to be applied into clinics.

- Although both passive and active neuron targeted approaches have been studied, an active neuron-targeted approach that is based on the use of neuron-specific ligands to promote neuronal uptake sparing the other brain cells is the most desirable strategy.

- Novel active strategies such as the development of dual-ligand fusion peptides targeting neurons, neuronal mitochondria-targeted nanocarriers, and intranasal administration of exosomes selectively incorporated by neuronal cells in the pathological regions of brains have been recently developed.

\section{Conclusion \& future perspective}

- The development of innovative neuronal-targeting nanomedicines, particularly active targeting-based approaches, is a critical need in the treatment of neuronal disorders, filling the gap between laboratory and bedside treatment.

- The studies discussed in this review shed light on the use of nanotechnology as a promising strategy for specific delivery of drugs into neurons to treat neuronal-related diseases that are still unmet clinical issues. 


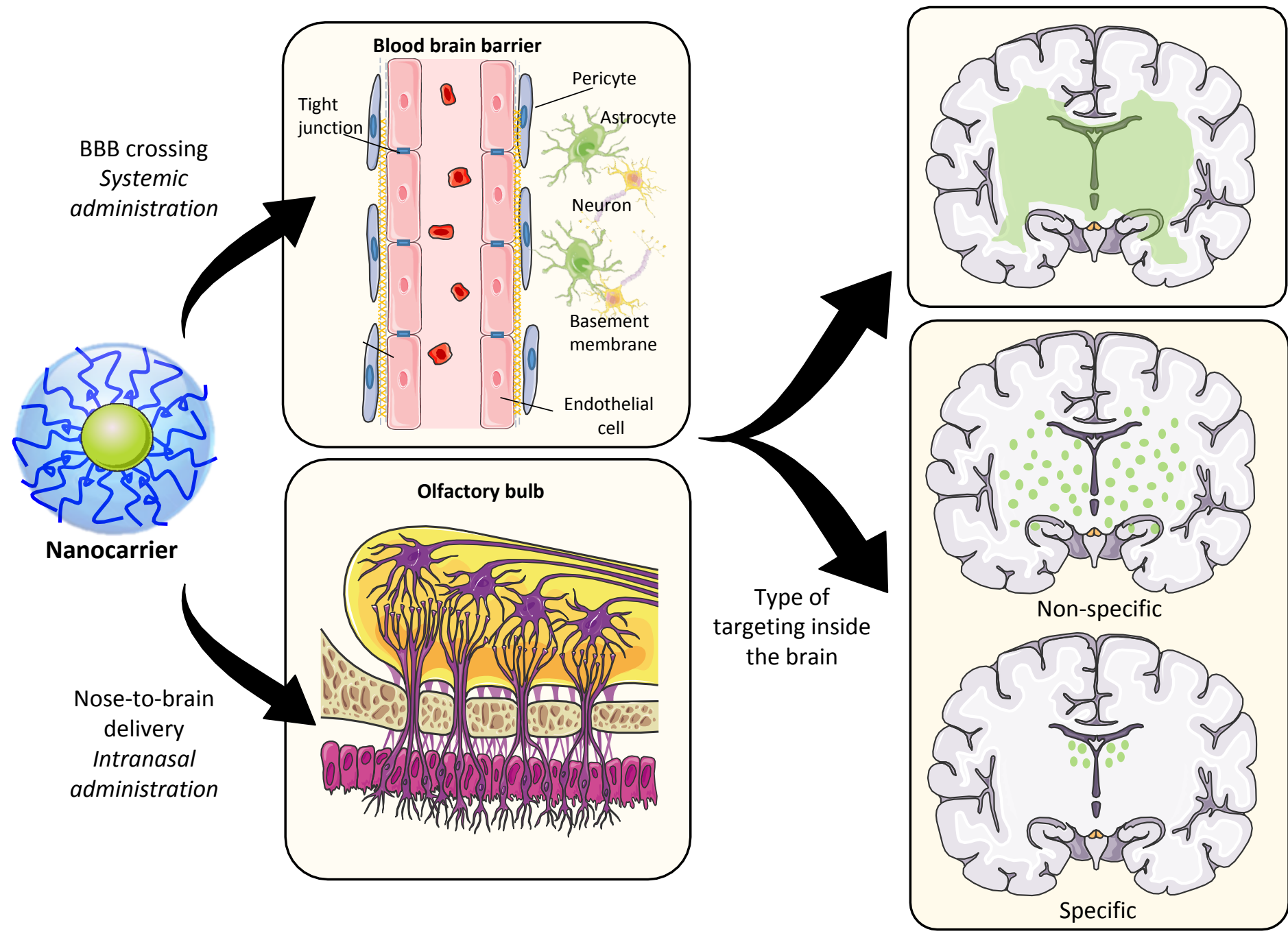

Passive neuron-targeted approaches

Active neuron-targeted approaches

Potential ligands:

- Tet1

- TrkA

- Lactoferrin

- RVG

- Ts1

- Antisauvagine-30 
Table 1. Nanoparticles in clinical use for the treatment of neurological disorders.

\begin{tabular}{|c|c|c|c|}
\hline Agent & $\begin{array}{l}\text { Nanoformulation } \\
\text { information }\end{array}$ & Therapeutic indication & $\begin{array}{l}\text { Clinical trial ID / } \\
\text { Current status }\end{array}$ \\
\hline $\begin{array}{l}\text { Glatiramer } \\
\text { acetate } \\
\left(\text { Copaxone }^{\circledR}\right) \\
{[53]}\end{array}$ & $\begin{array}{l}\text { Polymeric-based } \\
\text { therapeutic }\end{array}$ & Relapsing-remiting multiple sclerosis & FDA approved in 1995 \\
\hline $\begin{array}{l}\text { Peginterferon } \\
\text { Beta-1a } \\
\text { (PLEGRIDY®) } \\
{[55]}\end{array}$ & $\begin{array}{l}\text { Polymeric-based } \\
\text { therapeutic }\end{array}$ & Multiple sclerosis & FDA approved in 2014 \\
\hline \multirow{3}{*}{$\begin{array}{l}\text { Gold } \\
\text { nanocrystals } \\
\text { CNM-Au8 [75] }\end{array}$} & \multirow{3}{*}{$\begin{array}{l}\text { Suspension of clean- } \\
\text { surfaced, faceted, } \\
\text { gold nanocrystals in } \\
\text { sodium bicarbonate } \\
\text { buffered water }\end{array}$} & Amyotrophic lateral sclerosis & NCT04098406 / Phase 2 \\
\hline & & Parkinson's disease & NCT03815916 / Phase 2 \\
\hline & & $\begin{array}{l}\text { Remyelination Failure in Chronic Optic } \\
\text { Neuropathy In Multiple Sclerosis }\end{array}$ & NCT03536559 / Phase 2 \\
\hline $\begin{array}{l}\text { APH-1105 } \\
{[5,119]}\end{array}$ & - & Alzheimer's disease & NCT03806478 / Phase 2 \\
\hline \multirow[t]{2}{*}{$\begin{array}{l}\text { Nanocurcumin } \\
{[120,121]}\end{array}$} & \multirow[t]{2}{*}{$\begin{array}{l}\text { Curcumin } \\
\text { encapsulated in nano- } \\
\text { micelles }\end{array}$} & Relapsing-remiting multiple sclerosis & $\begin{array}{l}\text { Iranian Registry of } \\
\text { Clinical Trials number } \\
\text { IRCT2016042227520N1 }\end{array}$ \\
\hline & & Amyotrophic lateral sclerosis & $\begin{array}{l}\text { Iranian Registry of } \\
\text { Clinical Trials number } \\
\text { IRCT2015062411424N3 }\end{array}$ \\
\hline
\end{tabular}


Table 2. Main type of platforms used for brain delivery of therapeutics. Lipid-based, polymeric, inorganic, and cell-derived nanomedicines are shown, highlighting a few selected physicochemical characteristics focusing on neuron targeting.

\begin{tabular}{|c|c|c|c|}
\hline \multicolumn{2}{|c|}{ Type of nanomedicine } & \multirow{2}{*}{$\begin{array}{l}\text { Physicochemical properties relevant for neuron } \\
\text { targeting } \\
\text { - Liposomes are prepared from phospholipids, for } \\
\text { example dioleoyl or distearoyl } \\
\text { phosphatidylcholine. } \\
\text { - Liposomes with single lipid layers are generally } \\
25-100 \mathrm{~nm} \text {. }\end{array}$} & \multirow{2}{*}{$\begin{array}{l}\text { Ref. } \\
{[36,37,49]}\end{array}$} \\
\hline $\begin{array}{l}\text { Lipid-based } \\
\text { nanomedicines }\end{array}$ & Liposome & & \\
\hline & Lipoplex & $\begin{array}{l}\text { Lipoplexes are prepared from cationic lipids } \\
\text { having a cationic head and hydrophobic tail, for } \\
\text { example, Dioleoyl-3-trimethylammonium } \\
\text { propane (DOTAP). } \\
\text { - The size of lipoplexes varies widely, from } \\
\text { couple of } 100 \mathrm{~nm} \text { to couple of } \mu \mathrm{M} \text {. }\end{array}$ & [40-42] \\
\hline \multirow[t]{2}{*}{$\begin{array}{l}\text { Polymeric } \\
\text { nanomedicines }\end{array}$} & Polymer micelle & $\begin{array}{l}\text { Polymeric micelle has characteristic core-shell } \\
\text { structure with optimal size range of } 10-100 \mathrm{~nm} \text {. }\end{array}$ & {$[56,59,63]$} \\
\hline & $\begin{array}{l}\text { Polymer-protein } \\
\text { conjugate }\end{array}$ & $\begin{array}{l}\text { Polymer-protein conjugates are composite } \\
\text { macromolecules derived from covalently } \\
\text { combining protein and synthetic polymers. } \\
\text { - PEGylated interferon beta-1a, PLEGRIDY }{ }^{\circledR} \text {, is } \\
\text { a FDA approved drug for multiple sclerosis } \\
\text { (MS). }\end{array}$ & {$[55]$} \\
\hline $\begin{array}{l}\text { Inorganic } \\
\text { nanomedicines }\end{array}$ & Quantum rods & $\begin{array}{l}\text { - Semiconductor nanocrystals are made of } \\
\text { CdSe/CdS. } \\
\text { - Rod-shaped nanocrystals, the quantum rods } \\
\text { induce neuronal stimulation through its local } \\
\text { electric field associated with permanent dipole } \\
\text { moment. } \\
\text { - Surface modifications with different functional } \\
\text { groups can produce quantum rods with adaptable } \\
\text { surface charge. }\end{array}$ & {$[76-78,82]$} \\
\hline $\begin{array}{l}\text { Cell-derived } \\
\text { nanomedicines }\end{array}$ & $\begin{array}{l}\text { Exosomes with } \\
\text { AuNP }\end{array}$ & $\begin{array}{l}\text { Exosomes are lipid-bound membrane vesicles } \\
\text { with } 50 \text { to } 100 \mathrm{~nm} \text { in diameter. } \\
\text { - Structural flexibility of exosomes allows } \\
\text { encapsulating AuNPs. } \\
\text { - With adaptable size and shape AuNPs can act as } \\
\text { a support for various bio-macromolecules. } \\
\text { - Neuron-targeted exosomes were used to cover } \\
\text { AuNPs for efficient BBB penetration. }\end{array}$ & {$[83,88,89]$} \\
\hline
\end{tabular}


1 Table 3. Main in vivo studies using passive or active neuron-targeted nanoformulations in neurological diseases at the pre-clinical stage.

\begin{tabular}{|c|c|c|c|c|c|c|}
\hline $\begin{array}{l}\text { Type of } \\
\text { approach }\end{array}$ & Type of NP & NP-based approach and outcome & Type of cargo & Target disease & $\begin{array}{l}\text { Experimental in } \\
\text { vivo model }\end{array}$ & Reference \\
\hline \multirow[t]{5}{*}{$\begin{array}{l}\text { Passive } \\
\text { Neuron } \\
\text { Targeting }\end{array}$} & Polymeric & $\begin{array}{l}\text { PEGylated PLGA nanoparticles. } \\
\text { Increased drug availability in the brain and increased drug effectiveness against } \\
\text { the disease. }\end{array}$ & Memantine & $\begin{array}{l}\text { Alzheimer's } \\
\text { Disease }\end{array}$ & $\begin{array}{l}\text { APP/PS1 } \\
\text { transgenic mice }\end{array}$ & {$[93]$} \\
\hline & Polymeric & $\begin{array}{l}\text { B6 peptide-modified PEG-PLA nanoparticles. } \\
\text { B6 peptide (a transferrin substitute) is acting as specific ligand for } B B B \\
\text { crossing }\end{array}$ & $\begin{array}{l}\text { NAP peptide } \\
\text { (neuroprotective } \\
\text { peptide) }\end{array}$ & $\begin{array}{l}\text { Alzheimer's } \\
\text { Disease }\end{array}$ & $\begin{array}{l}\beta \text {-amyloid } \\
\left(\mathrm{A} \beta_{1-40}\right), \text { and } \\
\text { ibotenic acid (IBO) } \\
\text { coinjected mice }\end{array}$ & {$[103]$} \\
\hline & Polymeric & $\begin{array}{l}\text { Polyion complex micelle self-assembled from PEG-PLL(MPA/IM) block } \\
\text { copolymer. } \\
\text { The controlled glucose density on the surface of the nanocarrier allowed } \\
\text { regulation of its distribution in specific brain regions. This NP also allowed ASO } \\
\text { access to the brain after systemic administration. }\end{array}$ & $\begin{array}{l}\text { MALAT1 } \\
\text { lncRNA }\end{array}$ & $\begin{array}{l}\text { Spinal muscular } \\
\text { atrophy; } \\
\text { Alzheimer's } \\
\text { Disease }\end{array}$ & Balb/c mice & {$[95]$} \\
\hline & Polymeric & $\begin{array}{l}\text { Poly(L-lactic acid) crystalsomes [98]. } \\
\text { The crystalsomes exhibited positive zeta potential, } \\
\text { nanoscale range and longer releasing time for levodopa. Enhanced effectiveness } \\
\text { of the drug. } \\
\text { Chitosan nanoparticles [99]. } \\
\text { Nose to brain delivery of levodopa loaded in these NPS. The NPs were } \\
\text { incorporated in a thermo-reversible gel prepared using Pluronic PF127. } \\
\text { Increased brain uptake of the drug. }\end{array}$ & Levodopa & $\begin{array}{l}\text { Parkinson's } \\
\text { disease }\end{array}$ & $\begin{array}{l}\text { MPTP-induced } \\
\text { Parkinson's } \\
\text { diseases mouse } \\
\text { model }\end{array}$ & {$[98,99]$} \\
\hline & Polymeric & $\begin{array}{l}\text { PLGA nanoparticles. } \\
\text { Improved access of dopamine to the brain, lower accumulation in the periphery, } \\
\text { reducing side effects. Entering neurons, but also astrocytes. }\end{array}$ & Dopamine & $\begin{array}{l}\text { Parkinson's } \\
\text { disease }\end{array}$ & $\begin{array}{l}\text { 6-OHDA-induced } \\
\text { Parkinson's rat } \\
\text { model }\end{array}$ & {$[100]$} \\
\hline
\end{tabular}




\begin{tabular}{|c|c|c|c|c|c|c|}
\hline & Polymeric & $\begin{array}{l}\text { PLGA nanoparticles. } \\
\text { Intranasal administration of the nanoformulation enhanced brain targeting } \\
\text { efficiency, reduced the number of administrations compared to the free drug } \\
\text { controlling seizures and induced neuroprotection in rats }\end{array}$ & Oxcarbazepine & Epilepsy & $\begin{array}{l}\text { PTZ-induced } \\
\text { seizures rat model }\end{array}$ & [104] \\
\hline & Lipid-based & $\begin{array}{l}\text { LNPs prepared using tertiary amine-containing lipid derivatives that are } \mathrm{pH}- \\
\text { sensitive. } \\
\text { Neutral-surface LNPs lead to uniform gene expression in both astrocytes and } \\
\text { neurons when administered through the ICV route }\end{array}$ & eGFP mRNA & None & ICR mice & [46] \\
\hline & $\begin{array}{l}\text { Lipid/Inorga } \\
\text { nic hybrid }\end{array}$ & $\begin{array}{l}\text { SOD1 ASO was loaded into calcium phosphate nanoparticles, and then } \\
\text { encapsulated into a lipid layer (CaP-lipid). } \\
\text { CaP-lipid NPs showed time and concentration dependent internalization by } \\
\text { NSC-34 cells. They also diffused throughout zebrafish brain and spinal cord } \\
\text { after direct injection. }\end{array}$ & SOD1 ASO & $\begin{array}{l}\text { Amyotrophic } \\
\text { lateral sclerosis }\end{array}$ & $\begin{array}{l}\text { NSC-34 motor- } \\
\text { neuron like cells } \\
\text { and zebrafish }\end{array}$ & [49] \\
\hline & Polymeric & $\begin{array}{l}\text { Low-MW PEI-anti-SNCA siRNA complex. } \\
\text { siRNA complexed with this PEI extensively distributed across the CNS down to } \\
\text { the lumbar spinal cord after a single intracerebroventricular infusion. Lack of } \\
\text { data on successful delivery after IV administration of the nanoformulation. }\end{array}$ & $\begin{array}{l}\text { Anti-SNCA } \\
\text { siRNA }\end{array}$ & $\begin{array}{l}\text { Parkinson's } \\
\text { disease }\end{array}$ & $\begin{array}{l}\text { Mice } \\
\text { overexpressing } \\
\text { human SNCA } \\
\text { (Thy1-aSyn mice) }\end{array}$ & {$[50]$} \\
\hline & Polymeric & $\begin{array}{l}\text { PM prepared from PEG-PAsp(DET) and NEP mRNA } \\
P M \text { cell internalization internalization as well as NEP expression and activity } \\
\text { were confirmed both in vitro in mouse neurons and in vivo in mouse }\end{array}$ & NEP mRNA & $\begin{array}{l}\text { Alzheimer's } \\
\text { Disease }\end{array}$ & $\begin{array}{l}\text { Mice ICV injected } \\
\text { with } A \beta\end{array}$ & {$[60]$} \\
\hline $\begin{array}{l}\text { Active } \\
\text { Neuron } \\
\text { Targeting }\end{array}$ & Polymeric & $\begin{array}{l}\text { PEGylated poly(2-(N,N- dimethylamino) ethyl methacrylate) (PEG- } \\
\text { PDMAEMA). } \\
\text { Nanocomplexes decorated with cingulin (CGN) peptide for BBB crossing, and } \\
\text { the Tet1 peptide for neuron-specific binding. }\end{array}$ & $\begin{array}{l}\text { Anti-BACE1 } \\
\text { siRNA }\end{array}$ & $\begin{array}{l}\text { Alzheimer's } \\
\text { Disease }\end{array}$ & $\begin{array}{l}\text { APP/PS1 } \\
\text { transgenic mice }\end{array}$ & [107] \\
\hline & Inorganic & $\begin{array}{l}\text { Magnetic } \mathrm{Fe}_{3} \mathrm{O}_{4} \text { nanoparticles functionalized with oleic acid for stabilization and } \\
\text { decorated with NGF. } \\
N G F \text { on the surface targets the Tyrosine kinase receptors overexpressed in } 99 \% \\
\text { of cells, and N-isopropylacrilamide acrylic acid adsorbed to alpha-synuclein } \\
\text { shRNA. }\end{array}$ & $\begin{array}{l}\text { Anti-SNCA } \\
\text { shRNA }\end{array}$ & $\begin{array}{l}\text { Parkinson's } \\
\text { disease }\end{array}$ & $\begin{array}{l}\text { MPTP-induced } \\
\text { Parkinson's } \\
\text { diseases mouse } \\
\text { model }\end{array}$ & [111] \\
\hline
\end{tabular}




\begin{tabular}{|c|c|c|c|c|c|}
\hline Polymeric & $\begin{array}{l}\text { PAMAM and PEG NP loaded with GDNF and decorated with lactoferrin. } \\
\text { Expression of lactoferrin is increased in dopaminergic neurons in substantia } \\
\text { nigra, acting as a dual agent: ligand and also a repairing drug. }\end{array}$ & $\begin{array}{l}\text { Neurotrophic } \\
\text { factor: GDNF }\end{array}$ & $\begin{array}{l}\text { Parkinson's } \\
\text { disease }\end{array}$ & $\begin{array}{l}\text { 6-OHDA-induced } \\
\text { Parkinson's rat } \\
\text { model }\end{array}$ & {$[112]$} \\
\hline Polymeric & $\begin{array}{l}\text { PLGA NPs loaded with urocortin and decorated with lactoferrin. } \\
\text { Expression of lactoferrin is increased in dopaminergic neurons in substantia } \\
\text { nigra, acting as a dual agent: ligand and also a repairing drug. }\end{array}$ & Urocortin & $\begin{array}{l}\text { Parkinson's } \\
\text { disease }\end{array}$ & $\begin{array}{l}\text { 6-OHDA-induced } \\
\text { Parkinson's rat } \\
\text { model }\end{array}$ & [113] \\
\hline $\begin{array}{l}\text { Polymeric/ } \\
\text { Inorganic } \\
\text { hybrid }\end{array}$ & $\begin{array}{l}\text { Iron oxide functionalized with } 3 \text {-aminopropyltriethoxysilane (APTES). } \\
\text { As these nanoparticles can readily cross the BBB, the only decoration added is } \\
\text { antisauvagine-30, a peptide selective to corticotropin releasing factor receptor } 2 \\
\left(C R F_{2}\right) . C R F_{2} \text { mediates anxiety-like behaviour and it is a target for anxiolytic } \\
\text { drugs. Therefore, ASV-30 is in this case the guiding peptide, as well as the } \\
\text { delivered drug. }\end{array}$ & Antisauvagine-30 & Anxiety & $\begin{array}{l}\text { Rat model of } \\
\text { anxiety during } \\
\text { amphetamine } \\
\text { withdrawal }\end{array}$ & [114] \\
\hline Exosome & $\begin{array}{l}\text { Neuron-specific RVG peptide-modified exosomes. } \\
\text { The } R V G \text { peptide was fused to the extra-exosomal } N \text { terminus of Lamp } 2 b \text {, to } \\
\text { allow the exosomes to enter the brain efficiently. After IP administration, the } \\
\text { aptamers were delivered into the neuronal cells, blocking the pathological } \\
\text { formation of aggregates and decreasing neuron death. }\end{array}$ & $\begin{array}{l}\alpha \text {-synuclein- } \\
\text { recognizing DNA } \\
\text { aptamers }\end{array}$ & $\begin{array}{l}\text { Parkinson's } \\
\text { disease }\end{array}$ & $\begin{array}{l}\text { Mouse } \\
\text { intrastriatally } \\
\text { injected with } \alpha- \\
\text { synuclein } \\
\text { preformed fibril }\end{array}$ & {$[87]$} \\
\hline Polymeric & $\begin{array}{l}\text { TPL-modified PEG-PLA nanoparticles (TPL-NP). } \\
\text { Fusion peptide TPL comprising a BBB-penetrating peptide TGN and a neuron } \\
\text { binding peptide Tet1 through a four-glycine linker, for BBB and neuron } \\
\text { targeting, respectively. }\end{array}$ & $\begin{array}{l}\text { neuroprotective } \\
\text { peptide NAP }\end{array}$ & $\begin{array}{l}\text { Alzheimer's } \\
\text { Disease }\end{array}$ & $\begin{array}{l}\text { Mouse injected } \\
\text { with } A \beta_{1-42} \text { in } \\
\text { hippocampus }\end{array}$ & [106] \\
\hline Polymeric & $\begin{array}{l}\text { Neuronal mitochondria-targeted PEG-PLA micelles (CT-NM). } \\
\text { CT-NM decorated with an NCAM mimetic peptide C } 3 \text { for brain neuron specific } \\
\text { binding and the triphenylphosphonium for mitochondrial targeting. CT-NM } \\
\text { significantly increased the encapsulated resveratrol's concentration in the } \\
\text { neuronal mitochondria. }\end{array}$ & Resveratrol & $\begin{array}{l}\text { Alzheimer's } \\
\text { Disease }\end{array}$ & $\begin{array}{l}\text { APP/PSI transgenic } \\
\text { mice }\end{array}$ & [108] \\
\hline
\end{tabular}




\begin{tabular}{|c|c|c|c|c|c|}
\hline Exosome & $\begin{array}{l}\text { Mesenchymal stem cell (MSC)-derived exosomes. } \\
\text { The exosomes encapsulated AuNPs for easily tracking the brain distribution of } \\
\text { MSC-exo after intranasal administration in mice. The MSC-exo were selectively } \\
\text { uptaken by neuronal cells, but not glial cells, in the pathological regions. }\end{array}$ & No cargo & $\begin{array}{l}\text { Alzheimer, } \\
\text { Parkinson's } \\
\text { disease, Autism, } \\
\text { Stroke }\end{array}$ & $\begin{array}{l}\text { 6-OHDA induced } \\
\text { Parkinson's mice; } \\
\text { 5xFAD } \\
\text { Alzheimer's mice; } \\
\text { BTBR Autism } \\
\text { mice; ETH1-1 } \\
\text { induced stroke mice }\end{array}$ & [89] \\
\hline
\end{tabular}

2 